\title{
Genomic Patterns of Divergence in the Early and Late Steps of Speciation of the Deep-Sea Vent Thermophilic Worms of the Genus Alvinella
}

Camille Thomas-Bulle ( $\sim$ camille.thomas-bulle@umt.edu )

Sorbonne Université, CNRS, UMR, Station Biologique de Roscoff

Denis Bertrand

Genome Institute of Singapore

Niranjan Nagarajan

Genome Institute of Singapore

Richard Copley

Villefranche Oceanographic Laboratory

\section{Erwan Corre}

CNRS, FR2424, ABiMS, Station Biologique de Roscoff, Place Georges Teissier, 29680

\section{Stéphane Hourdez}

Observatoire Océanologique de Banyuls-sur-Mer

\section{Eric Bonnivard}

Sorbonne Université, CNRS, UMR, Station Biologique de Roscoff

\section{Adam Claridge-Chang}

Institute of Molecular and Cell Biology

Didier Jollivet

Sorbonne Université, CNRS, UMR, Station Biologique de Roscoff

\section{Research Article}

Keywords: Divergence, genome architecture, speciation, ecological species, habitat specialization, selection, hydrothermal vents

Posted Date: March 7th, 2022

DOI: https://doi.org/10.21203/rs.3.rs-1405281/v1

License: (1) (1) This work is licensed under a Creative Commons Attribution 4.0 International License.

Read Full License 


\section{Genomic patterns of divergence in the early and late steps of speciation of the}

\section{2 deep-sea vent thermophilic worms of the genus Alvinella.}

4 Camille Thomas-Bulle ${ }^{1,2^{*}}$, Denis Bertrand ${ }^{3}$, Niranjan Nagarajan ${ }^{3,4}$, Richard Copley ${ }^{5}$, Erwan

5 Corre $^{6}$, Stéphane Hourdez ${ }^{7}$, Éric Bonnivard ${ }^{1}$, Adam Claridge-Chang $^{8}$, Didier Jollivet ${ }^{1}$

${ }^{1}$ Sorbonne Université, CNRS, UMR 7144 AD2M, Station Biologique de Roscoff, Place Georges

8 Teissier CS90074, 29688 Roscoff, France.

${ }^{2}$ Emlen Lab, Division of Biological Sciences, University of Montana, Missoula, MT, USA

${ }^{3}$ Genome Institute of Singapore, 60 Biopolis Street, \#02-01 Genome, Singapore 138672,

13 Singapore.

${ }^{4}$ National University of Singapore, 21 Lower Kent Ridge Road, Singapore 119077, Singapore.

${ }^{5}$ Sorbonne Université, CNRS, UMR 7009 LBDV, Laboratoire 'Evolution des génomes et des protéines animales', Observatoire océanologique, Quai de la Darse, 06234, Villefranche/mer, cedex, France.

${ }^{6}$ CNRS, FR2424, ABiMS, Station Biologique de Roscoff, Place Georges Teissier, 29680, France.

${ }^{7}$ Sorbonne Université, CNRS UMR 8222, Laboratoire d'Ecogéochimie des Environnements Benthiques (LECOB), Observatoire Océanologique de Banyuls, Avenue du Fontaulé, 66650 Banyuls-sur-mer.

${ }^{8}$ Duke-NUS Medical School, Institute of Molecular and Cell Biology, 61 Biopolis Drive 8-05B, 138673 Singapore.

*Corresponding author: Camille Thomas-Bulle: camille.thomas-bulle@mso.umt.edu

34 Divergence, genome architecture, speciation, ecological species, habitat specialization, selection, 35 hydrothermal vents 
39 Background: The transient and fragmented nature of the deep-sea hydrothermal environment made of ridge subduction, plate collision and the emergence of new rifts is currently acting to the

41 separation of vent populations, local adaptation and is likely to promote bursts of speciation and

42 species specialization. The tube-dwelling worms Alvinella pompejana called the Pompeii worm

43 and its sister species A. caudata live syntopically on the hottest part of deep-sea hydrothermal

44 chimneys along the East Pacific Rise. They are exposed to extreme thermal and chemical gradients,

45 which vary greatly in space and time, and thus represent ideal candidates for understanding the

46 evolutionary mechanisms at play in the vent fauna evolution.

47 Results: In the present study, we explored genomic patterns of divergence in the early and late 48 steps of speciation of these emblematic worms using transcriptome assemblies and the first draft 49 genome to better understand the relative role of geographic isolation and habitat preference in their 50 genome evolution. Analyses were conducted on allopatric populations of Alvinella pompejana

51 (early stage of separation) and between A. pompejana and its syntopic species Alvinella caudata

52 (late stage of speciation). We first identified divergent genomic regions and targets of selection as

53 well as their position in the genome over collections of orthologous genes and, then, described the

54 speciation dynamics by documenting the annotation of the most divergent and/or positively

55 selected genes involved in the isolation process. Gene mapping clearly indicated that divergent 56 genes associated with the early stage of speciation, although accounting for nearly $30 \%$ of genes, 57 are highly scattered in the genome without any island of divergence and not involved in gamete 58 recognition or mito-nuclear incompatibilities. By contrast, genomes of A. pompejana and A. 59 caudata are clearly separated with nearly all genes (96\%) exhibiting high divergence. This 
60 congealing effect however seems to be linked to habitat specialization and still allows positive

61 selection on genes involved in gamete recognition, as a possible long-duration process of species

62 reinforcement.

63 Conclusion: Our analyses pointed out the non-negligible role of natural selection on both the early

64 and late stages of speciation in the emblematic thermophilic worms living on the walls of deep-

65 sea hydrothermal chimneys. They shed ligth on the evolution of gene divergence during the

66 process of speciation and species specialization over a very long period of time.

68 Background

The transient and fragmented nature of the deep-sea hydrothermal environment made of

71 ridge subduction, plate collision and the emergence of new rift systems likely led to the separation

72 of vent communities at a large spatial scale with transient events of spatial isolation and bursts of

73 speciation [1-4]. Most species inhabiting these unstable and harsh environments often display a

74 rapid growth, a fast maturation, a high investment in reproduction relative to survival and good

75 dispersal abilities enabling the colonization of vent emissions as soon as they appear [5-6]. Many

76 studies notably focused on how this highly specialized and endemic fauna disperse and colonize

77 new territories in the face of habitat fragmentation [7-8]. Given the dynamics of the vents

78 associated with the tectonic activity along oceanic ridges and its effect on the metapopulation

79 dynamics [9], such environment appears ideal to study the mechanisms by which speciation occurs

80 and to tease apart the relative role of geography and local adaptation to this extent. On one hand,

81 the vent environment is highly variable with abrupt chemical gradients leading to a mosaic of

82 habitats where species are spatially and temporally partitioned [10-12]. This may likely promote 
83 ecological speciation when migration is not able to counter-balance local selection at some specific

84 locations. On the other hand, populations are connected within a linear network of habitats and

85 tectonic plates rearrangements are likely to result in either species spatial isolation or secondary

86 contact zones where hybridization can occur [3, 13-16]. In addition to isolation by distance

87 between vent populations, patterns of genetic differentiation are mainly explained by the presence

88 of physical barriers to dispersal such as transform faults, microplates, triple junction points or

89 zones of weaker hydrothermal activity [3,15-16]. These relatively dynamic geological features

90 may produce vicariant events in the faunistic composition of vent communities [17] that often

91 coincide with the appearance of barriers to gene flow and hybrid zones $[14,16,18]$.

92 Early incipient species often represent groups of individuals that can still interbreed and

93 exchange genes despite the emergence of pre- or post-zygotic barriers to gene flow. During the

94 process of speciation and even at the latest steps of reinforcement, emerging species are thus not a

95 collection of impermeable taxonomic units with distinct morphologies but rather dynamic entities

96 gradually heightening their reproductive barriers in a more or less continuous way over long

97 periods of time [19]. This process depends on the divergence history of the populations and their

98 associated ecological changes. But it is worth mentioning that exceptions where speciation

99 happens relatively fast also exist, for example in the case of genomes under disruptive selective

100 conditions following changes in ploidy [20-21] or rapid shifts in reproductive timing/behaviour

101 due to the colonization of new territories/habitats [22-23]. In general, pre- and post-zygotic

102 mechanisms leading to reproductive isolation result in a gradual accumulation of genetic barriers

103 during the separation of groups of individuals in either space or time [24-31]. The point at which

104 speciation is initiated and then considered complete is however vague and varies with the species

105 concept used (e.g., complete reproductive isolation, hybrid counter-selection, phylogenetic 
106 isolation with complete sorting of allelic lineages between populations). In the initial part of the

107 speciation process, individuals are likely to still exchange genes across semi-permeable barriers

108 resulting in heterogeneous migration rates along the genome but could also endure local adaptation

109 resulting in a loss of genetic diversity over some portions of their interacting genomes [32].

110 Recent studies on the genetic architecture of reproductive isolation across the entire 111 genome often found a genome-wide heterogeneity of genetic differentiation between populations, 112 ecotypes or even well-separated morphological species, with highly divergent regions of the 113 genome contrasting with regions of lower divergence rather than a homogeneous rate of 114 differentiation across the genome [30,33-34]. To this extent, genome scans of differentiation and 115 genome-wide linkage maps based on polymorphic sites at multiple loci across the genome, 116 represent powerful tools to address the genomic landscape of population/species isolation. Regions 117 displaying high levels of differentiation between lineages, so-called "genomic islands of 118 speciation" were logically assumed to exhibit loci underlying reproductive isolation when the time 119 elapsed since isolation was long enough to create genetic incompatibilities [35]. Most of the time, 120 "islands of speciation" are believed to result from local barriers to gene flow at some specific genes 121 that rapidly led to allele fixation, gene hitchhiking and the subsequent accumulation of divergence 122 [36]. These islands differ from incidental islands of divergence resulting from accelerated rates of 123 lineage sorting within populations due to recurrent events of either selective sweeps or background 124 selection not necessarily related to reproductive isolation [37]. The genomic island metaphor has 125 proven popular and a wide array of studies searching for "islands of speciation" in multiple taxa 126 has been published over the last decade [30,34,35,38-42]. These studies identified outlier loci or 127 regions that stand out from the distribution of the multi-loci genetic differentiation (most often 128 through Fst scans) expected under models of migration with or without isolation and 
129 heterogeneous rates of migration across genomes (e.g., assortative mating, hybrid counter-

130 selection, divergent selection). Such outlier genes usually fall into three categories: (1) outliers

131 resulting from a differential effect of purifying selection in non-crossover regions of the separating

132 genomes, (2) outliers involved in Dobzhansky-Muller incompatibilities that affect the fitness of

133 hybrids/heterozygotes, and (3) outliers resulting from differential local adaptation between the

134 splitting lineages. In the last category, a limited number of alleles involved in local adaptation have

135 been found to carry a selective value strong enough to initiate a barrier to gene flow primarily by

136 divergent selection. When considering speciation from both ends of the road, how do these patterns

137 of divergence differ between the early and the late stages of isolation?

138 To better understand the role of genomic architecture on speciation, the number, width, and

139 level of clustering of divergent regions within the genome of early incipient species are usually

140 compared with more divergent congeneric pairs. It is expected that early in speciation, regions of

141 divergence should be small and randomly scattered in the genome and possibly restricted to a few

142 non-recombining regions. These regions may correspond to the accumulation of genetic

143 incompatibilities or to loci under diversifying selection strong enough to overcome gene flow

144 which would be expected to homogenize the rest of the genome. Conversely, later in speciation,

145 when gene flow is greatly reduced between the two genomes by the cumulated effect of multiple

146 genetic barriers, divergent selection, physical linkage between targets of selection and

147 chromosomal rearrangements may create longer genomic regions of divergence. Such processes

148 acting over larger regions of the genome, followed by gene specialization within each genome in

149 response to local adaptation contribute to a genome-wide "congealing" (GWC) effect that finalizes

150 speciation with reproductive isolation [43-46]. GWC refers to the period along the speciation

151 continuum when the genomes of the splitting populations essentially become sealed and when 
152 reproductive isolation becomes a property of the whole genome not just of a few loci [43].

153 Therefore, incomplete lineage sorting and semi-permeable barriers to gene flow (associated with

154 the early stages of speciation) and the wide synergetic effects of genome congealing due to

155 chromosomal linkage between diverging genes (associated with the latest stages) are likely to

156 result in very distinct patterns of divergence at a given stage of the speciation process. Moreover,

157 positive selection over the genome due to gene specialization under local conditions should affect

158 KEGG pathways differently over the course of the splitting process. Although fundamental to our

159 understanding of speciation, such comparisons between the early and late stages of speciation, and

160 the time of transition between these two stages have rarely been done when looking at the

161 relationship between the number of diverging genes in association (congealing effect) and their

162 accumulated divergence (time since species separation).

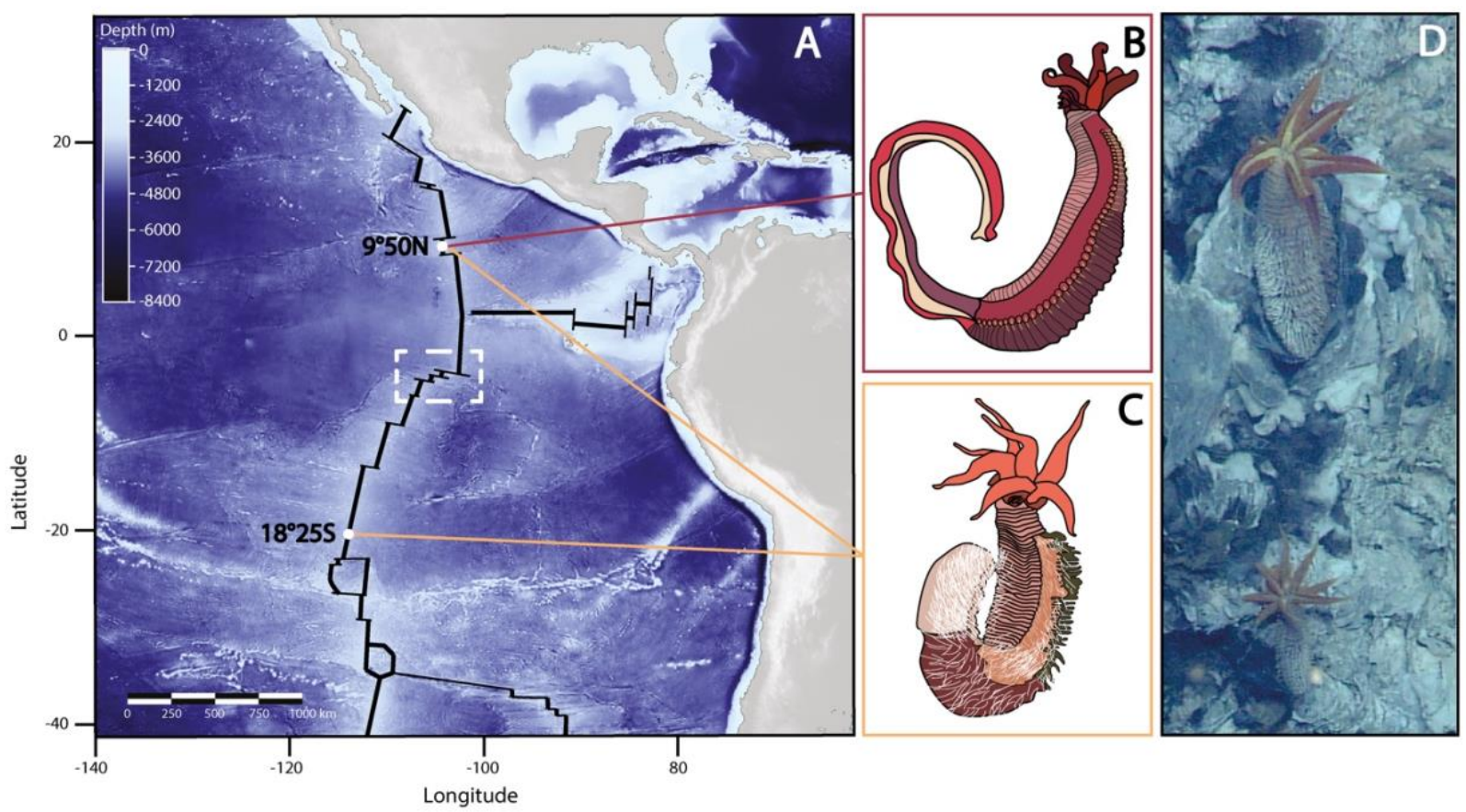

Figure 1: A) Bathymetric map of the East Pacific Ridge (in black), sampled populations sites along the ridge (white dots) and the geographical barrier between Southern and Northern populations (white dashed square); B) Drawing of a specimen of Alvinella caudata; C) Drawing of a specimen of Alvinella pompejana; D) A. pompejana, populations in situ (East Pacific Rise: $13^{\circ} \mathrm{N}, 2630 \mathrm{~m}$ ); PHARE cruise $\odot$ Ifremer 
In the present study, we explored genomic patterns of divergence in the early and late steps

166 of speciation of the emblematic Alvinella worms colonizing the hottest part of deep-sea

167 hydrothermal chimneys along the East Pacific Rise (EPR) (Figure 1) [47-48]. Using transcriptome

168 assemblies, we carefully examined the relative role of geographic isolation and habitat preference

169 in shaping gene divergence between newly isolated populations (in allopatry) of Alvinella

170 pompejana and between this latter species and its syntopic species Alvinella caudata (niche

171 specialization \& reinforcement in sympatry). The tube-dwelling worms Alvinella pompejana

172 Desbruyères \& Laubier 1980 [49] (Figure 1C and 1D) called the Pompeii worm and its sister

173 species A. caudata Desbruyères \& Laubier 1986 [50] (Figure 1B) live on the wall of still-hot

174 chimneys of the EPR from $23^{\circ} \mathrm{N}$ (Guaymas basin) to $38^{\circ} \mathrm{S}$ (Pacific-Antarctic Ridge). The first

175 description of these two worms considered them as two morphologically distinct ontogenic forms

176 of a single species, one juvenile form with a long tail bearing filamentous campylobacteria on

177 modified notopodia (corresponding to A. caudata) and the adult reproductive form without tail but

178 bearing the same epibionts on the whole dorsal part of its body (corresponding to A. pompejana).

179 But enzyme polymorphism analyses led to the subdivision of this taxon into two distinct species

180 without any shared electromorphs between them [51-52]. For both species, a strong physical

181 barrier to gene flow was depicted at the Equator near $7^{\circ} \mathrm{S} / \mathrm{EPR}$ and separates Northern and

182 Southern vent populations in two allopatric groups of putative cryptic species with differentiation

183 particularly marked in the Pompeii worm Alvinella pompejana [3,15]. Differences in the vent-site

184 turn-over from both sides of the EPR and its subsequent effect on local hydrothermal vent

185 conditions (i.e. changes in thermal conditions due to a highest proportion of still-hot chimneys and

186 fluid chemistry heterogeneity at both local and regional scales) could represent favorable

187 conditions for local adaptation and subsequent ecological filtering when migration is low or 
188 episodic across the barrier. In addition, depth gradient along the ridge or between ridges, extreme

189 variations in the hydrothermal fluid composition and subsequent effects on symbiotic associations

190 with divergent bacterial strains are likely to induce divergent selection between vent populations

$191 \quad[53]$.

192 To compare both ends of the speciation process, we performed the first genome scans of

193 both synonymous and non-synonymous gene divergences using transcriptome assemblies of the

194 two allopatric forms of A. pompejana that have recently separated about 1.5 Mya (early stage of 195 speciation), and that of its co-occurring sister species A. caudata, known to exhibit almost 196 complete reproductive isolation with A. pompejana (late stage of speciation). We then identified 197 divergent genomic regions and targets of selection as well as their position in the genome over 198 collections of orthologous genes and, thus, described the speciation dynamics by documenting the 199 annotation of the most divergent and/or positively selected genes involved in the species isolation.

Results

\section{Assembly and annotation of the reference genome and associated transcriptomes}

The assembled genome of $A$. pompejana consisted in 3,044 scaffolds for a total size of $205245 \mathrm{Mb}$, which represents $61 \%$ of the total genome size (400 Mb). The mapping of both divergence 206 and associated $\mathrm{d}_{\mathrm{N}} / \mathrm{d}_{\mathrm{s}}$ along scaffolds was however only performed on the 113 longest scaffolds (> $207300,000 \mathrm{bp})$ to maximize the number of genes per scaffold. 
211 Blastn alignments between the Northern and Southern transcriptomes of A. pompejana and 68,963

212 pairwise Blastn alignments between the transcriptomes of A. pompejana and A. caudata. As these

213 putative genes contain paralogs, tandemly repeated paralogs, allelic forms of a gene in either genes

214 with or without introns, we filtered our datasets to only keep a subset of the most likely orthologous

215 genes. This reduces the number of pairwise alignments to 22,558 and 48,134 respectively.

216 Determination and translation of the CDS with a minimum threshold length of $300 \mathrm{bp}$ and

217 sequence-similarity search against the Uniprot database reduced the two final datasets to 6,916

218 and 6,687 pairwise alignments of orthologous coding sequences on which further analyses were

219 performed.

220

221

Distribution of genetic divergence and $\mathrm{d}_{\mathrm{N}} / \mathrm{ds}_{\mathrm{s}}$ values

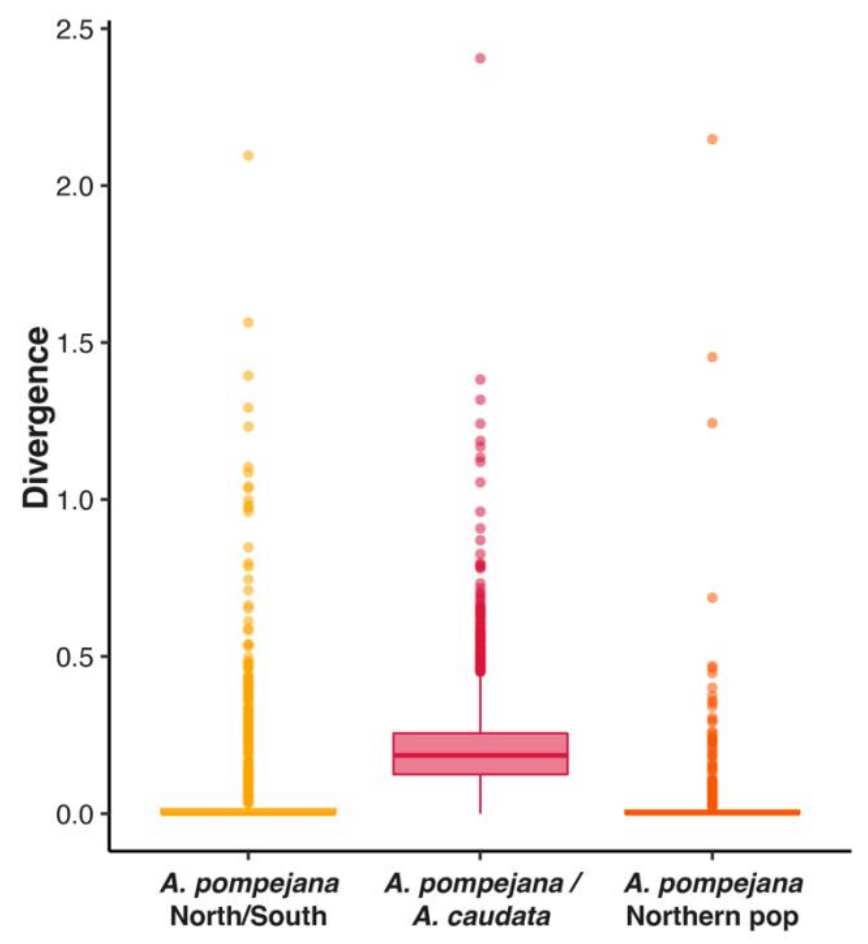


Figure 2: Boxplots of the distribution of the divergence values found in different stages of speciation in Alvinella spp. worms. The yellow color corresponds to the comparison A. pompejana south/north. The red color corresponds to the comparison A. caudata/A. pompejana. The orange color corresponds to the comparison A. pompejana Northern populations.

228 pairwise synonymous to non-synonymous substitution rates and the associated divergence 229 between orthologous transcripts of divergent individuals within and between closely-related 230 species (see the "Methods" section). Among the 6,916 orthologous genes studied between the two

231 Northern and Southern individuals of $A$. pompejana, 58\% of the coding sequences are strictly

232 identical with no nucleotide differences, $26 \%$ of the genes display divergences between $0.5 \%$ and

$2331.75 \%(0.01>t>0.05)$, and only $4 \%$ of the genes represent outliers that diverge by more than $2 \%$

$234(\mathrm{t}>0.05)$ along their sequence (Figure 2$)$. As expected in early speciation steps, the overall mean

235 divergence of genes is low $(\mathrm{t}=0.016)$ with values following a negative exponential distribution

236 with a long tail of outliers. However, the distribution has a slight bimodal shape, the second

237 unexpected mode being centered around a value ten times greater (i.e., about 0.020 substitution

238 per codon) (Figure 2). This bimodal shape was not encountered when assessing the intra-specific

239 allelic diversity between two Northern individuals (average diversity $=0.0096 \pm 0,0051$ with fewer

240 outliers $(\mathrm{t}>0.05=2 \%)$, see Figure 2$)$. Analysis of both transition and transversion rates between

241 individuals from North and South were 4 times greater than those found by comparing two distinct

242 individuals of the same population in the northern part of the EPR (Figure 3). 


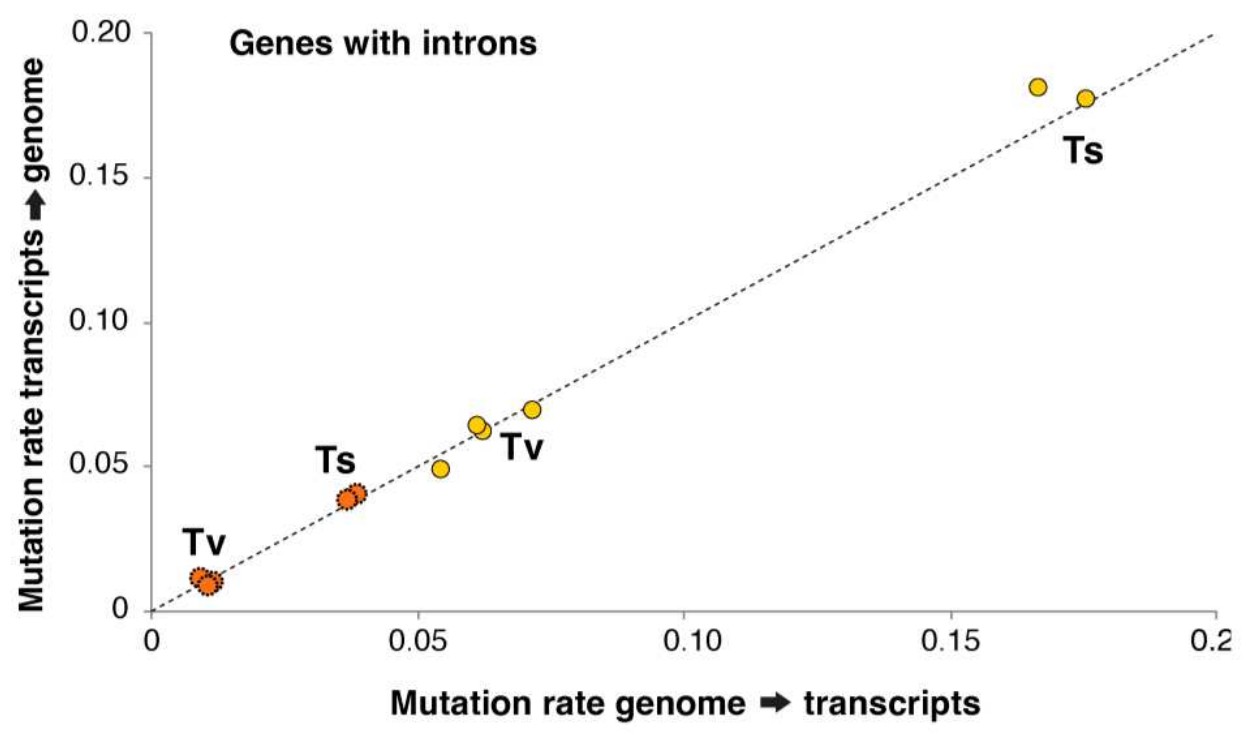

A. pompejana Northern populations ○ A. pompejana North/South

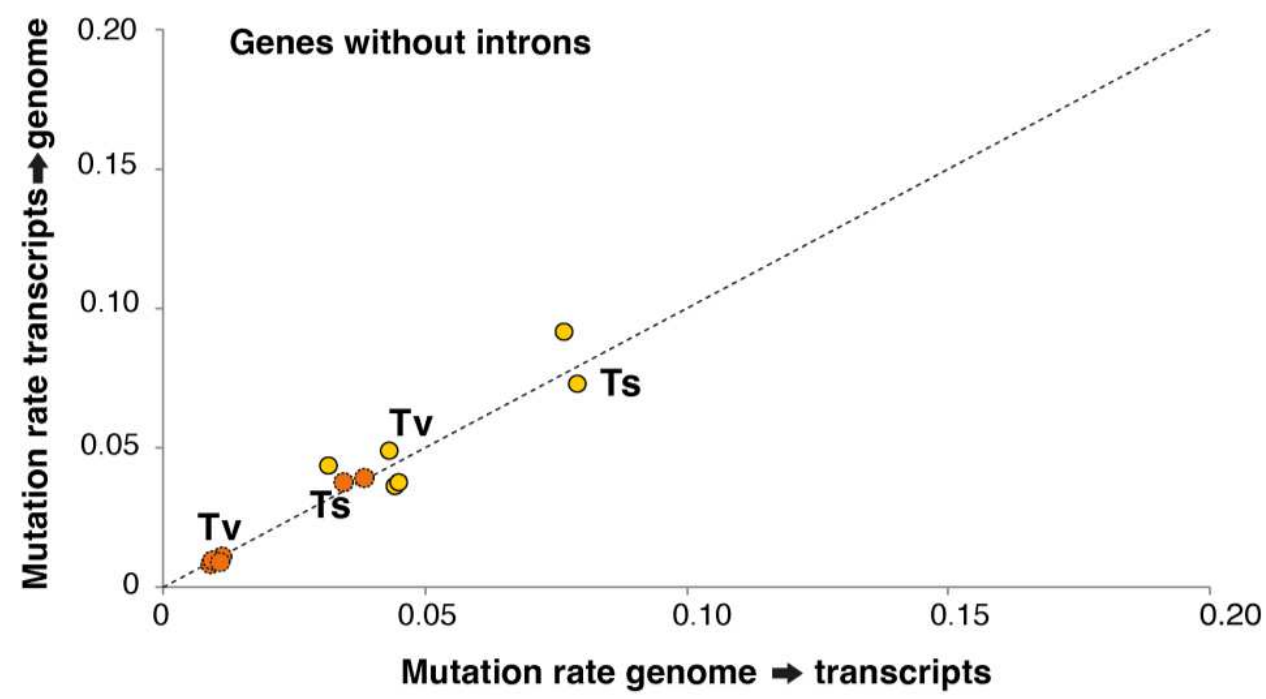

244 Figure 3: Transition and translation rates obtained between orthologous pairs of genes of Alvinella pompejana 245 by comparing single-individual transcriptomes from the north $\left(9^{\circ} 50 \mathrm{~N}\right)$ and south $\left(18^{\circ} 25 \mathrm{~S}\right)$ EPR onto the genome of the worm (northern individual). Rates were obtained from coding sequences obtained from the 246 orthologous gene datasets used for the $\mathrm{d}_{\mathrm{N}} / \mathrm{d}_{\mathrm{S}}$ analysis by discriminating genes without introns and genes with 247 introns (i.e. the exonic regions of genes obtained after mapping transcripts onto the genome). 
On the opposite, the large majority of the 6,687 genes are highly divergent between $A$.

251 pompejana and A. caudata. Divergence follows a Gaussian distribution centered around 0.2

252 substitution per codon with an asymmetric tail of outliers (Figure 2). Only $0.4 \%$ of the sequences

253 are strictly identical with no nucleotide differences corresponding to only 33 pairwise alignments,

$2543 \%$ of the genes display divergence levels between $10 \%$ and $25 \%(0.25>t>0.75)$, and $96 \%$ of the 255 genes diverge by more than $25 \%(t>0.75)$ along their sequence. Thus, the distribution of the 256 divergence between A.caudata and the 2 populations of A.pompejana is significantly different 257 (Figure 2; Wilcoxon test, $\mathrm{p}<2.2 \mathrm{e}-16$ ), but this distribution is not significantly different within $A$. 258 pompejana populations (Wilcoxon test, $\mathrm{p}=0.8266$ ).

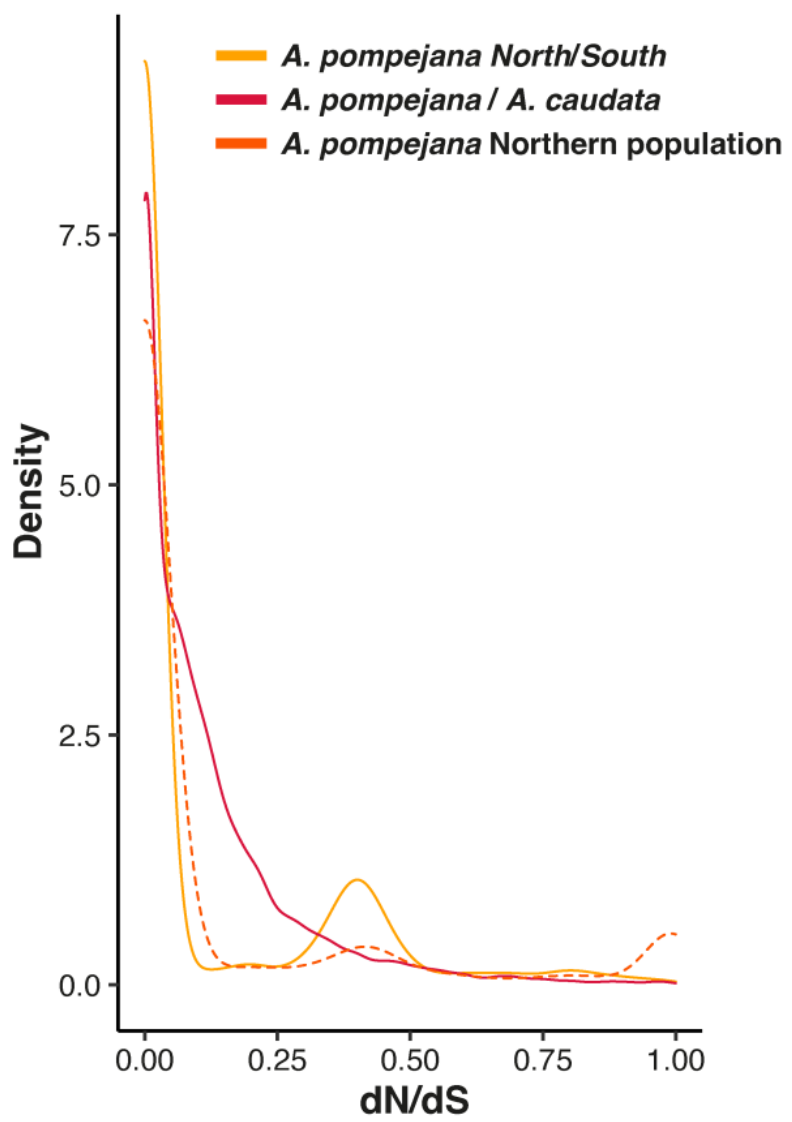

Figure 4: Density distributions of $\mathrm{d}_{\mathrm{N}} / \mathrm{d}_{\mathrm{S}}$ values estimated for each pairwise alignment of orthologous genes in both the early and late states of speciation in Alvinella spp. worms using the method of Nielsen \& Yang 261 (1998) implemented in PamlX. The yellow color corresponds to the comparison A. pompejana south/north. The red color corresponds to the comparison A. caudata/A. pompejana. The orange color corresponds to the comparison A. pompejana Northern populations. 
Regarding the distribution of the $\mathrm{d}_{\mathrm{N}} / \mathrm{ds}$ values between North and South individuals of $A$.

263 pompejana, most of the genes are non-divergent with a $\mathrm{d}_{\mathrm{N}} / \mathrm{d}_{\mathrm{s}}$ ratio set to zero (Figure 4 ). Among

264 diverging genes, $44 \%$ of the genes are under strong purifying selection with $\mathrm{d}_{\mathrm{N}} / \mathrm{ds}_{\mathrm{s}}$ values lower

265 than $0.25 .36 \%$ of the $\mathrm{d}_{\mathrm{N}} / \mathrm{d}_{\mathrm{s}}$ values are distributed in a small peak between 0.25 and 0.5 , and $6 \%$

266 of the genes are under positive selection with $\mathrm{d}_{\mathrm{N}} / \mathrm{d}_{\mathrm{s}}$ values higher than 1 and represent about $3 \%$

267 of the total number of genes examined (Figure 4). This peak of $d_{N} / d_{s}$ was not encountered when

268 comparing the two northern A. pompejana transcriptomes although the number of outliers

$269\left(\mathrm{~d}_{\mathrm{N}} / \mathrm{d}_{\mathrm{S}}>1\right)$ was higher between sequences of these two specimens (about 12\%). The absolute values

270 of $d_{N} / d_{S}$ and $\pi_{N} / \pi_{S}$ were greater than the $2 \%$ of genes under positive selection $\left(d_{N} / d_{S}>1\right)$ found

271 between $A$. pompejana and A. caudata, probably because of a sampling bias in estimating both

272 synonymous and non-synonymous rates from poorly intra-specific divergent sequences. The

273 remaining $\mathrm{d}_{\mathrm{N}} / \mathrm{d}$ s values lesser than one between A. pompejana and A. caudata (98\%) contains

274 about $30 \%$ of genes with $\mathrm{d}_{\mathrm{N}}$ equal to zero (i.e., "frozen" proteins), about $53 \%$ of genes with $\mathrm{d}_{\mathrm{N}} / \mathrm{d}_{\mathrm{S}}$

275 values ranging from 0 to 0.25 (genes under strong to moderate purifying selection) and $15 \%$ of

276 genes evolving under more relaxed conditions (close to one). The distribution of $\mathrm{d}_{\mathrm{N}} / \mathrm{d}_{\mathrm{S}}$ values

277 within and between species was significantly different (Wilcoxon test, $\mathrm{p}<2.2 \mathrm{e}-16$ ) with a clear

278 bi- to tri-modal distribution of the $\mathrm{d}_{N} / \mathrm{d}_{\mathrm{S}}$ values in the specific case of the within-species

279 comparison. The average $\mathrm{d}_{\mathrm{N}} / \mathrm{ds}$ estimated for both early and late steps of speciation was nearly

280 equal with values of 0.14 and 0.17 , respectively. In other words, at least $86 \%$ and $84 \%$ of non-

281 synonymous mutations are deleterious and do not fix in the two Alvinella worms. This represents

282 a minimum estimate of the fraction of strongly deleterious mutations because even a small number

283 of advantageous mutations will contribute disproportionately to divergence [54]. 


\section{Early stage of speciation (A. pompejana south/north comparison)}

Among the 41 genes under positive selection $\left(\mathrm{d}_{\mathrm{N}} / \mathrm{d}_{\mathrm{S}}>1\right)$ for which $\mathrm{d}_{\mathrm{N}} / \mathrm{d}_{\mathrm{s}}$ values remained

290 significant after the resampling test of the $\mathrm{d}_{\mathrm{N}} / \mathrm{d}_{\mathrm{s}}$ difference and the FDR procedure, only 12 of 291 them were annotated in the UniProt database. These genes are encoding proteins involved in (1) 292 transcription/translation/replication regulation and biosynthesis (ribosomal protein rpl19, GTP293 binding protein 1, elongation factor 1alpha, zinc finger protein GLI1) some of which being 294 involved in a wide variety of biological functions including spermatogenesis, (2) endocytosis and 295 immunity regulation, which may play a crucial role in the worm's epibiosis (Rab5 protein, CD209 296 antigen protein A), (3) neuro-transmission regulation (complexin) and the development of sensory 297 organs (protein mab-21), (4) development of nephridies, and possibly gonoducts in alvinellids 298 (actin-binding Rho protein), (5) mRNA methylation (pre-miRNA 5'-monophosphate 299 methyltransferase), and (6) setae/modified hook formation that should influence 300 reproductive/thermoregulatory behavior (chitin synthase).

In the same way, among the 102 orthologous genes between A. caudata and A. pompejana 305 for which $\mathrm{d}_{\mathrm{N}} / \mathrm{d}_{\mathrm{S}}$ values were greater than one, only 37 remained significant after the resampling 306 test of the $\mathrm{d}_{\mathrm{N}} / \mathrm{d}_{\mathrm{s}}$ difference and the FDR procedure but, in this case, most them were annotated (31 307 genes) in the UniProt database. These genes encode for proteins involved in (1) carbohydrate 
308 catabolism (deoxyribose-phosphate aldolase), (2) immunity (innate and adaptive), viral responses,

309 apoptosis (fibrinogen-like protein, lysosomal protective protein, acetylcholine receptor), (3)

310 steroid/lipid metabolism and membrane composition (transmembrane protein, 3-oxo-5-alpha-

311 steroid 4-dehydrogenase, methylsterol monooxygenase, protein DD3-3-like), and tegument

312 structure (actin, collagen, epidermal growth factor named fibropellin, GTP-binding protein,

313 protein-methionine sulfoxide oxidase MICAL1), (4) sexual differentiation,

314 spermatogenesis/oogenesis, sperm adhesion (zonadhesin, innexin), (5) DNA damage repairs and

315 methylation (ATP-dependent RNA helicase DDX51 and DDX58, poly-(ADP-ribose) polymerase,

316 forkhead box G1 protein WD repeat-containing protein), oxidative stress response and protein

317 glycosylation (beta-1.3-galactosyltransferase 5-like, C19orf12), (6) cell proliferation/apoptosis,

318 mitosis, neuron formation (Tumor Necrosis Factor alpha, ras-related protein, APC/C activator

319 Cdc20 protein, tyrosine-protein kinase, protein FAM134C, zinc finger protein), and (7) signaling

320 mediated by metals (metabotropic glutamate receptor). Despite a suspected several millions of

321 years of species separation, it is worth-noting that positive selection is still acting on genes

322 involved in reproductive isolation, namely on zonadhesin and innexin, hence possibly reinforcing

323 species boundaries.

Patterns of nucleotide substitutions and highly divergent genes

Because natural selection usually operates mostly on the non-synonymous sites (but also

328 on translational accuracy [55]), the relative values of $\mathrm{d}_{\mathrm{N}}$ and $\mathrm{d}$ may provide a key for making

329 inferences about the adaptive evolution of protein-coding genes. Usually, the synonymous rate is

330 three times greater than the rate of substitutions at nonsynonymous sites but should be equal under 
331 neutral evolution. Thus, the depression in non-synonymous substitution rate is interpreted as being 332 caused by natural selection eliminating deleterious mutations to comply with both the 3D structure

333 and functions of proteins. The relationship between these two relative rates of substitutions was

334 assessed in the early and late steps of speciation thanks to a linear regression to take into account

335 the very high variance of these rates. The two comparisons greatly differ in the slope and intercept

336 of the linear regression between $\mathrm{d}_{\mathrm{N}}$ and $\mathrm{ds}_{\mathrm{S}}$ (A. pompejana North/South: $\mathrm{y}=0.002631+0.040525 \mathrm{x}$;

337 A. pompejana / A. caudata: $\mathrm{y}=0.01818+0.01186 \mathrm{x})$ (Figure 5).

338

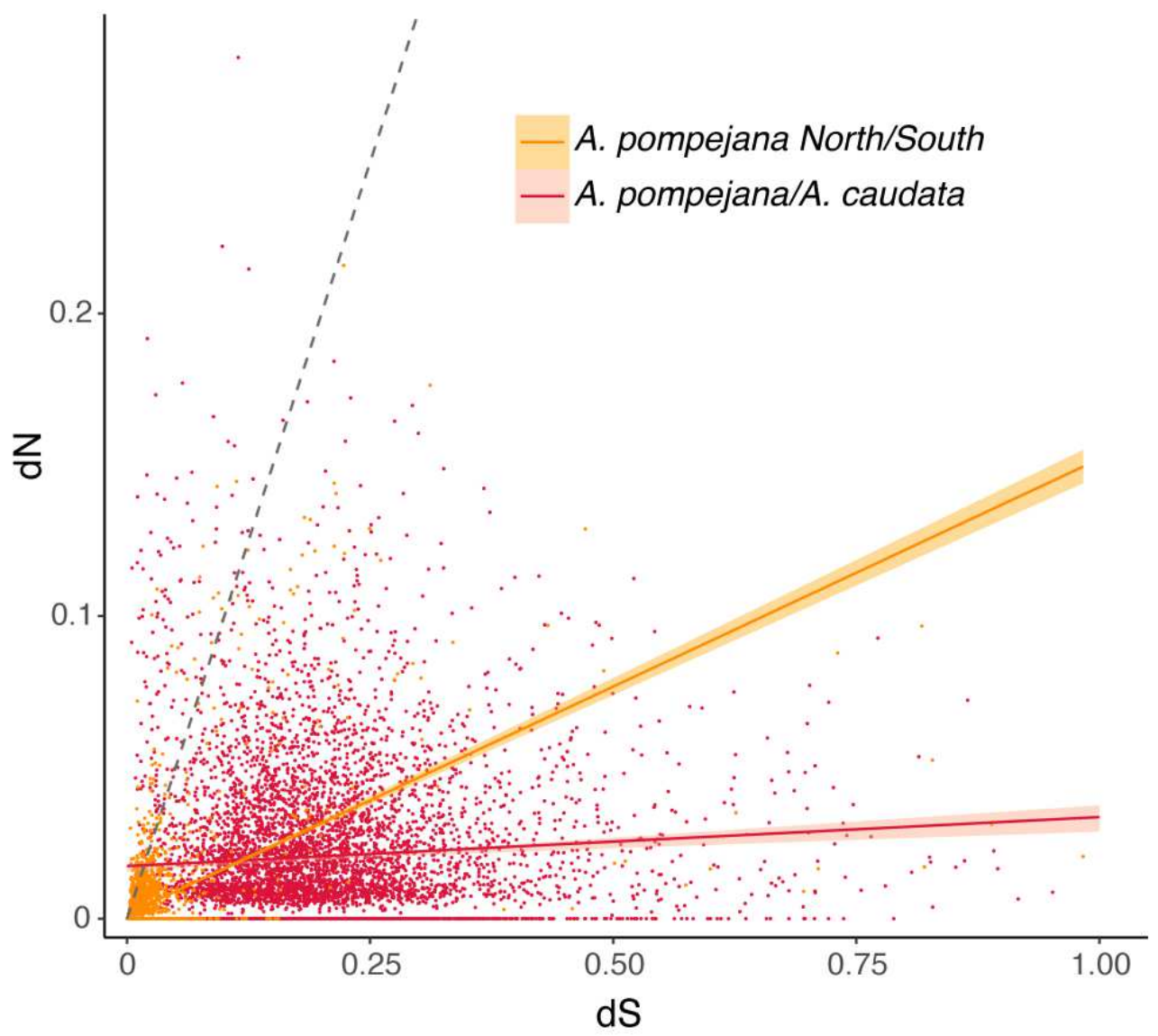

$340 \quad$ Figure 5: Rates of synonymous and non-synonymous divergences between A. pompejana North and South populations (yellow) and A. pompejana and A. caudata (red). The grey dashed line represents the expected linear relationship between $\mathrm{d}_{\mathrm{S}}$ and $\mathrm{d}_{\mathrm{N}}$ under neutral evolution. 
The number of highly divergent genes (i.e. in the tail distribution of the genes) is almost

344 five times greater (92 vs 20 annotated genes) and much more diversified when comparing the late

345 and early stages of speciation, respectively. Interestingly, most genes with saturated ds rates in the

346 early step of speciation are either histone deacetylases or belong to the tubulin multigene family

347 (Supplementary Table 1). Most $\alpha$ - and $\beta$-tubulins are under strong purifying selection (indicated

348 by the relatively low rate of non-synonymous mutations) but are likely to contain at least one or

349 two non-synonymous substitutions in their divergence, suggesting that the family may have

350 endured a burst of duplications, and subsequent independent lineages sorting from both sides of

351 the East Pacific Rise barrier. In contrast, most of the 92 annotated genes with a high evolutionary

352 rate in the late step of speciation encode for a wide range of functions (e.g., replication, translation,

353 intracellular transport...), which are quite similar to those also depicted for positively-selected

354 genes in the Ap/Ac comparison. More specifically, highly divergent genes which also exhibited

355 fixed non-synonymous substitutions were also found in steroid/phospholipid metabolism

356 (phospholipid-transporting ATPase, sphingolipid delta(4)-desaturase, fatty acid-binding protein,

357 inositol polyphosphate 5-phosphatase), carbohydrate catabolism and the tricarboxilic cycle

358 implied in the worm's epibiosis with specific production of acetyl-CoA (carbohydrate

359 sulfotransferase4 dihydrolipoyllysine-residue acetyltransferase, acyl-CoA synthetase), cell

360 motility, spermatogenesis, and egg-sperm fusion (dynein, integrin, disintegrin, protocadherin),

361 embryonic and neuron development (methenyltetrahydrofolate synthase, protein sidekick),

362 membrane (nidogen-1, lipoprotein receptor1, EH domain-containing protein3, transmembrane and

363 coiled-coil domain-containing protein1, spectrin) and tegument organization (HHIP-like hedgehog

364 protein1, biotin, $\alpha$-actinin) but also, proteins more targeted on putative "adaptive" molecular

365 pathways such as oxidative and thermal stress response (peroxidase, peroxiredoxin 4, glutathione 
peroxidase, Hsp70, Hsp83), DNA repairs and methylation (ATP-dependent RNA helicase, DNA

367 ligase1, RNA polymerase II transcription subunit, adenosylhomocysteinase B, BRCA1-associated

368 RING domain protein1, histone deacetylase3), mRNA A-to-I editing (Double-stranded RNA-

369 specific adenosine deaminase, xanthine dehydrogenase), protein glycosylation (Protein O-linked-

370 mannose beta-1.2-N-acetylglucosaminyltransferase1), adaptation to hypoxia (Hypoxia-inducible

371 factor1, carbonic anhydrase) and proteins involved in protein homo- heterodimerization

372 (complement factor $\mathrm{H}$-related protein2, $\mathrm{BTB} / \mathrm{POZ}$ domain-containing protein7).

Distribution of divergence and associated $\mathrm{d}_{\mathrm{N}} / \mathrm{ds}_{\mathrm{s}}$ along the genome

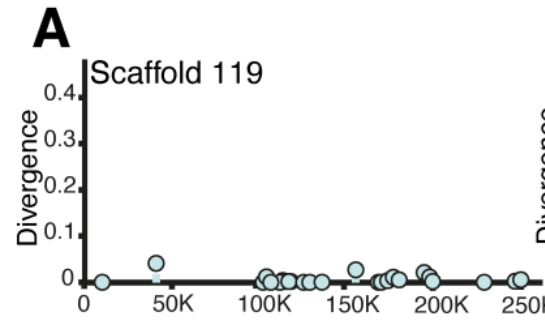

$\square$ No divergent gene
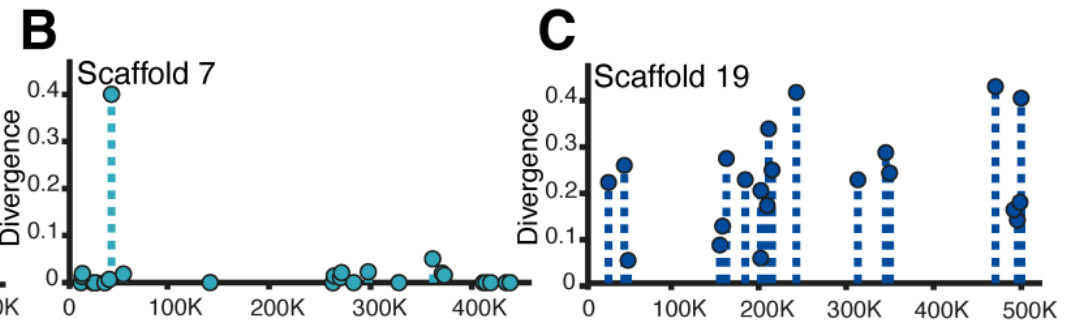

$\square$ Punctual divergent gene(s)
Group of divergent genes

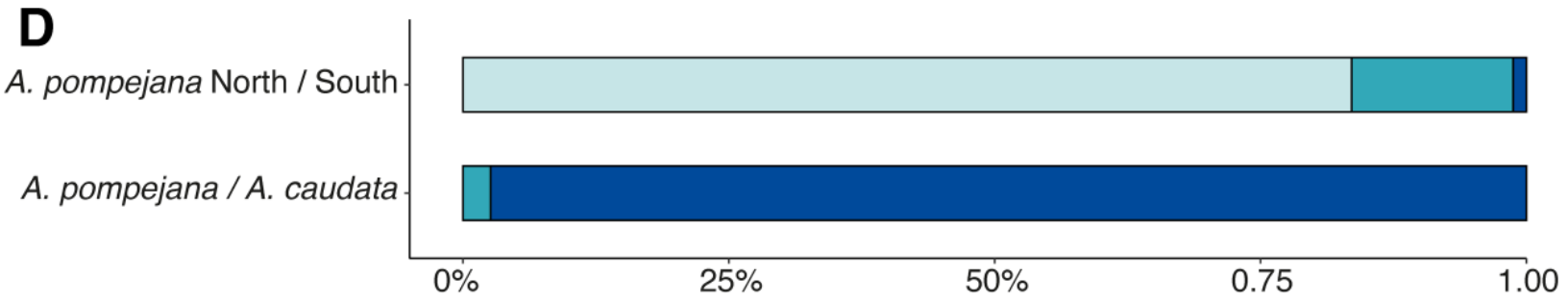

Figure 6: Genomic distribution of the divergence along the longest scaffolds ( $>400,000 \mathrm{bp})$ A. pompejana draft genome (subset of genes representing about $1 / 10$ of the genome). According to the index of distribution and our criterion of selection by eye, three distribution patterns of the divergence are found along scaffolds: (A) no divergent gene identified on the scaffold (in light blue), (B) sporadic presence of one divergent gene on a scaffold (in turquoise), and (C) group of spatially linked divergent genes (in dark blue). The relative proportion of each genomic pattern is shown in (D). 
The distribution of gene divergence was examined over the 79 scaffolds exceeding 300,000

382 bp with the A. pompejana North/South comparison (Figure 6D). Because the global level of

383 divergence is low and close to zero, values of divergence are homogeneously distributed with a

384 few punctual observable outliers. As a consequence, about $83 \%$ of the examined scaffolds have no

385 divergent genes (Figure 6A and 6D). Scaffolds containing only one divergent gene (Figure 6B and

386 6D) account for $15 \%$ of the examined portion of the genome and only one of the largest scaffolds

387 displays an island of divergence pattern, and may be linked to sexual chromosome (Figure 6C and

388 6D). On the contrary, for the A.caudata/A.pompejana comparison, divergence is clearly structured

389 along the genome in large islands of highly divergent genes for 97\% of the scaffolds (Figure 6D).

390 Each of the 76 scaffolds only carries very few genes with no divergence and we were not able to

391 identify any region or island of no divergence among the examined scaffolds. Here, divergence is

392 clearly structured in large blocks where all the genes and their putative exons are divergent. The

393 average values of $d_{N} / d_{s}$ per scaffold are globally homogeneous between scaffolds but the

394 dispersion index of the $\mathrm{d}_{\mathrm{N}} / \mathrm{ds}$ values around this mean fluctuates substantially. Gene density among

395 scaffold however greatly varies and therefore impacts the number of genes involved in the

396 genomes congealing. 


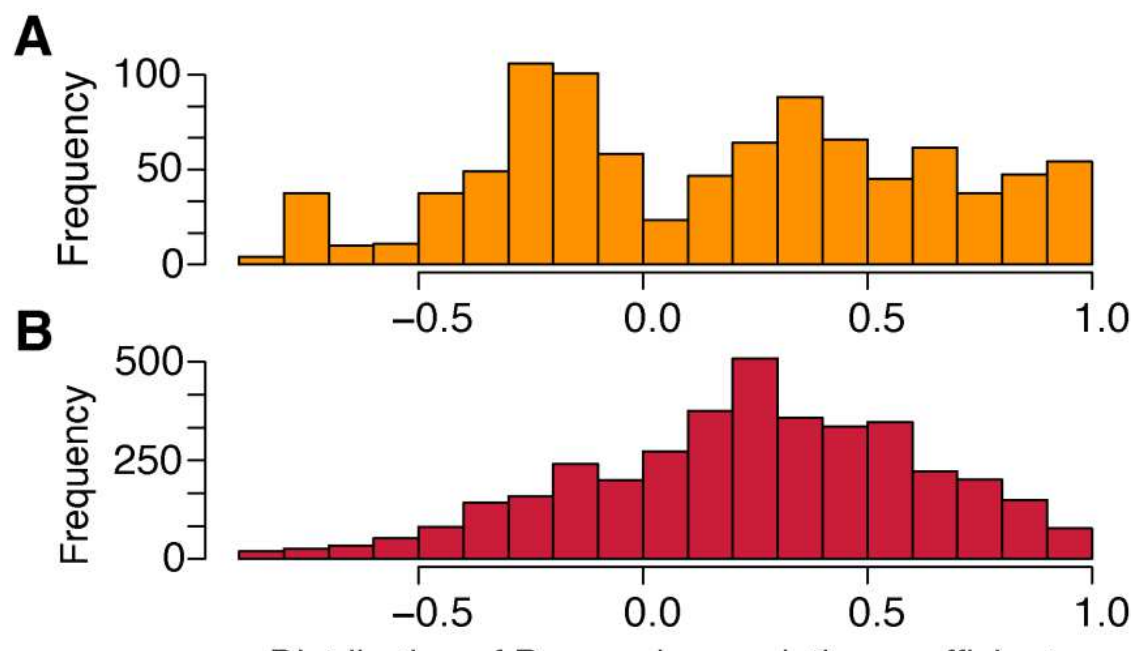

399 Figure 7: Distribution of the Pearson's correlation coefficient between divergence and associated dN/dS values calculated for each scaffold containing more than 5 genes: (A) A. pompejana North/South in yellow and (B) A. pompejana / A. caudata in red.

For both the early and late stages of speciation, no correlation between $\mathrm{ds}$ and $\mathrm{d}_{\mathrm{N}}$ has been

403 found over the whole set of orthologous genes (The North/South A. pompejana comparison: $404 \mathrm{r}=0.18, \mathrm{p}<2.2 \mathrm{e}^{-16}$, The A. caudata/A. pompejana comparison: $\left.\mathrm{r}=0.07, \mathrm{p}=1.794 \mathrm{e}^{-08}\right)$. We therefore 405 estimated the Pearson's correlation coefficient within each scaffold to uncover putative islands of 406 divergence and analyzed the distribution of this coefficient among scaffolds. The distribution of 407 the Pearson's coefficient is almost bimodal and symmetrical around zero during the early stage of 408 speciation (Figure 7A). Because most genes are weakly divergent (i.e., close to zero), this may 409 indicate that scaffolds segregate into two distinct patterns: polymorphic genes for which allelic 410 lineage sorting is incomplete and where the $\mathrm{d}_{\mathrm{N}} / \mathrm{d}_{\mathrm{S}}$ is biased by excesses of deleterious/artifactual 411 mutations and (2) genes for which allelic lineage sorting is completed with a fixed divergence 412 where positive selection may have acted. In contrast, the distribution of the correlation coefficients 413 displayed a clear shift towards a positive correlation between divergence and associated $\mathrm{d}_{\mathrm{N}} / \mathrm{d}_{\mathrm{s}}$ 414 values during the late stage of speciation (Figure 7B). Because most genes are highly divergent, 
415 this overall increase of $\mathrm{d}_{\mathrm{N}} / \mathrm{ds}$ with divergence therefore suggests that most of the genes have

416 evolved to adapt to a new ecological niche after the separation of the two sister species.

\section{Discussion}

Considering the speciation continuum from one end to the other is essential to shed light

421 on the mechanisms by which genomes separate, and more specifically the timing of reproductive

422 isolation and species specialization. In this study, we first examined an early stage of allopatric

423 speciation between populations of the Pompeii worm, Alvinella pompejana geographically

424 separated by a physical barrier to gene flow at the Equatorial triple junction of the East Pacific

425 Rise and the Galapagos rift $[3,17]$. This geographic separation of the Pompeii worm populations

426 is also associated with different venting dynamics related to different spreading rates of the ridge

427 segments that may play a crucial role in the proportion of still-hot chimneys and colder vent

428 habitats and thus the distribution of the microbiota/biota [8,56]. Then we also examined the

429 molecular evolution signature associated with a much more advanced stage of the speciation

430 process that separated A. pompejana and its syntopic sister species A. caudata, which exhibits a

431 slightly different niche. This event is relatively old and possibly predates the separation of the EPR

432 and the North East Pacific ridge $(\mathrm{JdF})$ communities by vicariance that led for example to the

433 separation of sibling species like Paralvinella pandorae pandorae and P. p. irlandei, about 28

434 Mya [1]. Mitochondrial and nuclear divergences estimated between A. pompejana and A. caudata

435 are indeed greater than those estimated for these latter species (supplementary data in [57]). 
To investigate the effect of "neutral" evolution and both "negative" and "positive"

438 selection along genomes of separating species, we estimated both divergence and $\mathrm{d}_{\mathrm{N}} / \mathrm{d}_{\mathrm{S}}$ values

439 from a collection of orthologous genes by comparing transcriptomes of $A$. pompejana and $A$.

440 caudata against a first draft of $A$. pompejana genome. Although the $\mathrm{d}_{\mathrm{N}} / \mathrm{d}_{\mathrm{S}}$ ratio is determined by

441 the combined effects of neutral, advantageous and deleterious mutations, it can tell us a lot about

442 the general impact of natural selection on the evolution of the coding portion of the genome. In

443 this context, a divergence scan on both synonymous and non-synonymous sites represents a very

444 powerful tool for tracing back the role of natural selection in the semi-permeability of diverged

445 genomes and the time at which these genomes started to congeal. It should be however noted that

$446 \mathrm{~d}_{\mathrm{N}} / \mathrm{ds}$ provides reliable information only for genes with complete lineage sorting where a

447 substantial amount of substitutions have become fixed between the separated genetic entities, and

448 caution must be taken during the early steps of speciation where most of loci are still polymorphic.

449 On the other side of the speciation spectrum, highly divergent genomes may also contain a large 450 number of saturated sites that leads to an overestimation of the $\mathrm{d}_{\mathrm{N}} / \mathrm{ds}$ ratio in fast-evolving genes.

During the early steps of speciation, the large majority of genes (about 70\%) are stacked

453 around null values of $d_{N}$ and $d_{s}$ but the relationship between the two rates for the remaining genes

454 is on average 5:1, one non synonymous substitution for five synonymous ones, probably due to 455 unfixed mutations in the worm's polymorphism. Allele divergence and associated $\mathrm{d}_{N} / \mathrm{d}_{\mathrm{S}}$ 456 distributions between (North vs South individuals) and within (North individuals) the Pompeii 457 worm's populations are indeed quite similar although a greater number of higher values has been 458 observed in the first comparison. This can be partially explained by the fact that the Equatorial 459 barrier to gene flow is not completely sealed [15] allowing rare episodes of allele introgression. 
460 On the opposite, the slope of the regression line between $\mathrm{d}_{\mathrm{N}}$ and $\mathrm{ds}$ is close to zero during the late

461 steps of speciation and clearly highlights a large accumulation of synonymous substitutions close

462 to saturation for a large number of genes. This strongly suggests that even if a great number of 463 non-synonymous substitutions are positively-selected, most of this signal is likely to have been

464 erased in fast-evolving genes. Outlier genes associated with high evolutionary rate $\left(\mathrm{d}_{\mathrm{s}}>0.5\right)$ should

465 thus represent fast-evolving genes that may have endured duplications, selective losses or gains of 466 duplicates according to habitat/geographic isolation during the early steps of speciation, but also 467 genes that may have already lost their 'adaptive' signal in the face of saturation at synonymous 468 sites during the late steps of speciation.

As a general observation across many taxa, the average value of $\mathrm{d}_{\mathrm{N}} / \mathrm{d}_{\mathrm{s}}$ over genes between 471 closely-related species is around 0.20 [58-60]. Multiple species comparisons suggest that more 472 than $70 \%$ of the whole set of mutations are strongly deleterious in most species and up to nearly $47330 \%$ are slightly deleterious or neutral [61]. Information gathered with the present study is 474 consistent with nearly $87 \%$ of mutations being deleterious or slightly deleterious in Alvinella 475 worms $\left(\mathrm{d}_{\mathrm{N}} / \mathrm{ds}\right.$ mean $\left.=0.10-0.15\right)$. This suggests that the majority of Alvinella genes are under 476 strong purifying selection probably as a consequence of the extreme thermal conditions 477 encountered by the worms [57]. Given such background selection, it is highly possible that many 478 proteins with $\mathrm{d}_{\mathrm{N}} / \mathrm{d}_{\mathrm{S}}$ ranging from 0.5 to 1 share some history of positive selection, without any 479 possibility to test it. 
Results from our genome-wide study are consistent with previous results relying on the mitochondrial genome and some other genes in showing the geographic isolation of $A$. pompejana 486 populations across the Equator [15,62-63]. We indeed observed a clear signal of divergence at 487 nearly $30 \%$ of genes between the transcriptomes of the southern and northern individuals of $A$. 488 pompejana, despite a huge number of non-divergent genes (55\% of the total number of genes 489 examined). This emerging divergence corresponds to a modal value of 0.025 substitution per 490 codon and represents a 4-times increase of both transitional and transversional substitutions when 491 compared with pairwise alignments of the same orthologous genes between two distinct northern 492 individuals from the same population. This emerging divergence at the genome scale confirms the 493 ongoing allopatric speciation occurring for these lineages along the EPR possibly reinforced by 494 local adaptation. Time since the population splitting does not seem to have been however sufficient 495 to produce a specific genomic architecture of divergence (i.e., islands of speciation) as most of the 496 divergent genes are scattered among scaffolds. This may be explained by the fact that the predicted 497 North-to-South migration, though very low [15] could still be able to overcome population 498 differentiation over large portions of the genome and thus, would prevent genes from accumulating 499 fixed divergence. Alternatively, time since population splitting may still be too short to result in a 500 complete lineage sorting for most genes and the subsequent emergence of genetic 501 incompatibilities. According to Orr \& Turelli [64] the strength of reproductive isolation (i.e. fitness 502 load of putative hybrids) increases as a function of the squared number of newly fixed mutations 503 in separated populations. The number of fixed substitutions (and hence associated genetic 504 incompatibilities) between the two isolated entities represents 15560 substitutions in coding 505 sequences (as the product of 2,075 300-codons genes with a divergence of 0.025 substitutions per 
506 codon (30\% of the investigated genes)) for approximately $1 / 10$ of the whole genome. Compared

507 to other eukaryotic models (e.g., about 70,000 changes accumulated between sub-species of the

508 Drosophila simulans complex over 0.25 My [65] for about the same number of coding sequences),

509 the number of accumulated changes (i.e. 15,560) is quite low if the two populations separated 1.5

510 Mya [15], even if the generation time may be about 10 times greater in Drosophila. Such

511 discrepancy might be explained by a strong stabilizing selection associated with these extreme but

512 constant environmental conditions over space and time. Gene networks models indeed predict that

513 the hybrid incompatibility dynamics may be greatly reduced by stabilizing selection while

514 producing a "basin of attraction" for the optimal genotype on both sides of the barrier to gene flow $515[66]$.

In this early stage of speciation, very few genes showed evidence of positive selection and

518 these genes do not relate to genes currently depicted as involved in reproductive isolation (e.g.,

519 genes involved in gamete recognition, pheromones, mito-nuclear incompatibilities, hybrid sterility

520 or immune incompatibility [67-70]. Neither sperm-egg binding or egg-fusion proteins nor nuclear

521 proteins transferred to the mitochondria displayed signatures of positive selection or strong

522 divergence. However, almost all genes showing high evolution rates in our data encode for

523 tubulins, which represents highly diversified multigene families and can have a great influence on

524 cell division (mitosis/meiosis) and the spermatozoon flagellum architecture (which is extremely

525 reduced as a byproduct of the internal fertilization of oocytes in Alvinella [71]. It should also be

526 noted that a meaningful proportion of positively-selected genes could indirectly participate to the

527 establishment of reproductive barriers as they encode for proteins involved in spermatogenesis,

528 the development of gonoducts, the sensory system and setae/hooks that may play a role in male 
529 and female pairings (i.e., pre-zygotic isolation). Other genes under divergent selection are mostly

530 unknown or involved in immunity and endocytosis and may affect the interaction of the worm

531 with the associated campylobacteria-dominated microbial assemblages covering its tube and its

532 dorsal epidermis (i.e., trophic and detoxification role of the worm's epibiosis [72]). Microbial

533 communities are likely to be genetically different between vent fields as previously observed for

534 other vent taxa [73] and thus could induce co-evolutionary pathways of divergence in the worm's

535 immune system [74]. In the specific cases of sympatric or parapatric speciation, genes under

536 positive selection tend to be predominant among rapidly evolving genes [75]. Synergic effects

537 between positively-selected genes (linkage disequilibrium) are likely to produce local barriers to

538 gene flow if their number is high enough [30,46], but this is obviously not the case here. Analysis

539 of the correlation between divergence and $\mathrm{d}_{\mathrm{N}} / \mathrm{ds}$ revealed a potential antagonistic action of

540 selection on divergent genes, one half of scaffolds producing a negative correlation between the

541 two parameters whereas the other half exhibited a positive correlation. Such correlations are

542 clearly biased by the very high number of genes with no divergence but negative correlations over

543 many scaffolds could be interpreted as an excess of deleterious mutations due to incompletely

544 sorted polymorphisms for many genes. Additional work on the genetic differentiation of the two

545 separating lineages is currently undergone at both the genome and population scales using ddRAD

546 markers to complement this present study. 
As opposed to the recent history of allopatric speciation in A. pompejana, the scan of gene

552 divergence $\left(t, \mathrm{~d}_{\mathrm{N}}, \mathrm{d}_{\mathrm{s}}\right)$ between $A$. pompejana and its syntopic sister species $A$. caudata provides a

553 contrasting story of gene specialization after the congealing phase of the two corresponding

554 genomes. Our results confirm previous studies [51-52], who showed that these species did not

555 share any allele at enzyme loci and refuted the initial hypothesis that the two worms corresponded

556 to two morphological ontogenetic forms of the same species [49]. Both species occupy the same

557 hydrothermal vent habitat (hottest part of vent chimneys) and have exactly the same geographic

558 range from $21^{\circ} \mathrm{N} / \mathrm{EPR}$ to $38^{\circ} \mathrm{S} / \mathrm{PAR}$ (Pacific-Antarctic Ridge) leading to the possibility of

559 sympatric speciation. The two species indeed live in a spatially heterogeneous environment, which

560 greatly varies in time [76-77]. According to Gaill et al. [78], the parchment-like tube of the two

561 worms is highly thermostable, and the two species share many adaptations allowing them to thrive

562 in these waters loaded with heavy metals and sulfidic compounds (e.g., similar epibiotic flora

563 composition: [79], similar lipids in the cuticle: [80], similar branchial crown, gaz transfer structure

564 and haemoglobins [81-82], and same reproductive mode: [71]). Our study of gene divergence

565 however reveals a very old separation of the two species and a relatively high proportion of genes

566 (2\%) still showing evidence of positive selection when considering that the average gene

567 divergence is very high (i.e., close to 0.2 substitution per synonymous site). Most of the positively-

568 selected genes are not necessarily those with the highest rate of evolution, thus indicating that the

569 signal of positive selection may have been erased by excesses of synonymous substitutions for

570 many genes. Distribution of gene divergence appears quite homogeneous among scaffolds in terms

571 of basal divergence, which is a strong indication that a genome-wide congealing effect occurred

572 much earlier. We estimated the time of genome congealing around 26.5 Mya by using the

573 substitution rate previously estimated by Chevaldonné et al. [83]. The first mapping of divergence 
574 and associated $\mathrm{d}_{\mathrm{N}} / \mathrm{ds}$ showed however a strong heterogeneity of these variables along the genome

575 with some scaffolds having relatively higher divergence values. Although we cannot rule out that

576 these scaffolds could represent either regions of lower recombination rates or a portion of sex-

577 linked chromosome, their high divergence could also trace back to the early steps of the speciation

578 process (i.e. primary islands of speciation), in this case suggesting that the separation of the two

579 species may have been initiated much more earlier.

Gene divergence is also slightly positively correlated with $\mathrm{d}_{N} / \mathrm{ds}_{\mathrm{s}}$ within each scaffold. This

582 therefore suggests that the increase in gene divergence have been accompanied by the

583 accumulation of non-synonymous mutations. Assuming that $\mathrm{d}_{\mathrm{N}} / \mathrm{ds}$ only increase when

584 synonymous sites become saturated, this trend could either indicate an adaptive divergence

585 associated with a long period of gene specialization for the two sister species regarding their habitat

586 after their separation, or that the time since species separation is so high that most genes reached

587 saturation but this later interpretation does not fit well with the presence of positively-selected

588 genes. The genes under positive selection $\left(\mathrm{d}_{N} / \mathrm{d}_{\mathrm{s}}>1\right)$ are more specifically involved in the

589 repair/replication/biosynthesis of nucleic acids but also in several metabolic pathways usually

590 involved in the stress response, carbohydrate catabolism and lipid/steroid metabolisms associated

591 with membrane organization and tegument formation. Targets of positive selection seem to be

592 consistent with gene specialization in response to different thermo-chemical regimes encountered

593 by the worms, and more specifically high temperatures, natural doses of radioactivity and high

594 concentrations of sulfides and heavy metals producing reactive oxygen species (ROS) and reactive

595 sulfur species (RSS), and suggest that the two species do not share exactly the same niche.

596 Annotation of fast evolving genes also revealed that most of them belonged to exactly the same 
metabolic pathways impacted by positive selection including membrane/tegument organization.

598 Regarding fast evolving genes, we noted a net enrichment in proteins involved in oxidative stress 599 response (peroxidase, Hsps), adaptation to hypoxia, DNA repairs and methylation, mRNA A-to-I 600 editing, and protein glycolysation. The two latter molecular processes represent a powerful way to 601 adapt to differing thermal regimes [84-85]. These results therefore indicate that the adaptive 602 evolution of the two species has been a sufficiently 'old' process to erase most signatures of 603 positive selection that has likely played a crucial role in their ecological isolation. As opposed to 604 A. caudata, A. pompejana is one of the first colonizer of newly-formed and still hot chimneys [86] 605 when these edifices are made of porous anhydrite (barium/calcium sulfates) with temperatures 606 above $100^{\circ} \mathrm{C}$. Consistently, slight differences in terms of protein composition with more charged 607 residues in A. pompejana and more hydrophobic/aromatic ones in A. caudata have been described 608 [57]. Interestingly, when looking at the proportion of each species between chimneys at a local 609 spatial scale (i.e., hundreds of meters), it can be observed that newly-formed anhydrite edifices 610 and 'white smokers' are mostly inhabited by A. pompejana, whereas older edifices and 'black 611 smokers' are mainly characterized by a greater abundance of A. caudata [7]. Accelerated 612 differentiation of genes involved in the adaptive response of the worms to environmental variations 613 are likely to explain their different ecologies and behaviors to cope with 'high' temperatures. For 614 instance, tubes of the two species are closely entangled in colonies but with differences in their 615 opening [72] (D. Jollivet, pers. obs.). While the aperture of the tube of $A$. pompejana is widely 616 opened like a funnel with septa, that of $A$. caudata is ended by a small hole. The shape of the tubes 617 is likely related to the thermoregulatory behavior of the worms that helps individuals to refresh 618 their microenvironment through water pumping $[77,87]$. While A. pompejana is widely observed 619 moving inside and outside its tube to refresh it with the cold surrounding waters, $A$. caudata usually 
620 stays in its tube but exhibits a tail without organs used to cultivate its epibiotic flora that may be

621 viewed as a thermal sensor to position the worm at exactly the right temperature.

Despite this very long history of speciation and subsequent species specialization, one of

624 the most striking observations we made is that many genes involved in gamete recognition (e.g., 625 zonadhesin, innexin) are under positive selection, suggesting that species sympatry may still play

626 a role in species reinforcement. These positively-selected proteins are accompanied by several

627 fast-evolving proteins involved in spermatogenesis, and egg-sperm fusion (e.g., dynein, integrin,

628 disintegrin, protocadherin), and embryonic development (e.g., methenyltetrahydrofolate

629 synthase). Moreover, specific pathways such as the Acetyl-CoA cycle (3 targets) together with a

630 lipid desaturase seems to become highly differentiated. In Drosophila, desaturase genes and the

631 Acetyl-CoA cycle are both involved in the production of cuticular hydrocarbons (CHCs) which

632 have a crucial role in adaptation to desiccation and also act as pheromones involved in mating

633 behavior [70]. It is therefore possible that these two worm species preliminary evolved in a

634 different geographical context for a long period of time and then met secondarily during the

635 recolonization of the EPR after the episodes of tectonic isolation that structured the hydrothermal

636 fauna between 11-18 Mya as recently suggested to explain the phylogeographic patterns of the

637 Lepetodrilus elevatus complex of limpet species [4]. This rather late evolution of prezygotic

638 mechanisms of isolation contrasts with the allopatric situation encountered between the northern

639 and southern populations of A. pompejana and supposes that these mechanisms could last for a 640 very long time even after a genetic barrier has been erected. 


\section{Conclusion}

644 Our analyses pointed out the non-negligible role of natural selection on both the early and

645 late stages of speciation in the emblematic thermophilic worms living on the walls of deep-sea

646 hydrothermal chimneys. They shed ligth on the evolution of gene divergence during the process

647 of speciation and species specialization over time. Due to habitat fragmentation, populations

648 separate and start to accumulate putative adaptive mutations (and possibly genetic

649 incompatibilities) in allopatry where they find differing local conditions but are likely to

650 consolidate reproductive isolation in sympatry following secondary contacts during the

651 specialization process, even after genomes diverged almost completely (congealing effet). These

652 first analyses raise many further questions about the evolutionary mechanisms that led to the

653 speciation of Alvinella spp. and their subsequent distribution within the spatial micro-mosaic of

654 habitats typifying hydrothermal vents. Additional studies combining polymorphism and

655 divergence are needed to better understand the respective roles of geographic and ecological

656 histories of the worm's populations in speciation in a such fragmented and instable environment.

$658 \quad$ Material and methods

950N/EPR. Several DNA purification methods using alcohol precipitation and/or column

663 purification resulted in DNA samples that could not be efffectively digested by restriction

664 enzymes. To reduce mucopolysaccharides or similar co-precipitating contaminants, we purified

665 the DNA from worm tissue with phenol extraction and isopropanol precipitation followed by a 
666 clean-up step with cesium chloride gradient ultracentrifugation [88]. The DNA was used to prepare

667 paired-end shotgun and $5 \mathrm{~kb}$ mate-pair libraries for Illumina genome sequencing [89].

668

669 We used at least two additional individuals of $A$. pompejana and A. caudata coming from the same

670 locality to perform RNA sequencing and the subsequent assembly of transcriptomes for the

671 northern specimens of the two species [57]. In parallel, a Sanger sequencing project of a reference

672 and fully annotated transcriptome was performed using several individuals coming from a single

673 chimney of the hydrothermal vent field $18^{\circ} 25 \mathrm{~S}$ [90], for additional information about this

674 annotated transcriptome) and, represented the third transcriptome used to characterize the

675 specimens of A. pompejana located further south to the Equatorial barrier to gene flow previously

676 described $[3,15]$.

677

678 2) Sequencing (see Metrics in Supplementary Table 2)

679

680

- Genome and transcriptomes

681 Genome of the Pompeii worm (about $370 \mathrm{Mb}$ ) was sequenced from a single individual using both

682 a shotgun and mate-pair $5 \mathrm{~kb}$ sequencing using the Illumina HiSeq2500 technology at the A*Star

683 Molecular and Cell Biology Institute (Alvinella genome project: coord. A. Claridge-Chang).

684 Paired-end reads libraries (insert size 300bp) were assembled using SOAPdenovo2 (v2.0, -K 41 -

$685 \mathrm{~d}-\mathrm{R})$, contigs were then scaffolded with OPERA (v1.3.1) using both paired-end (insert size 300bp)

686 and mate pair libraries (insert size $5 \mathrm{~kb}$ ). Finally, the assembly was gapfilled with Gapcloser

687 (v1.12) to subsequently produce about 3000 scaffolds with a size greater than $15 \mathrm{~kb}$. 
688 The annotated transcriptome of the southern form of the Pompeii worm collected at the vent field

$68918^{\circ} 25 \mathrm{~S}$ has been already published in 2010 [90], and transcriptomes of the northern forms of $A$.

690 pompejana and A. caudata have been already published in 2017 [57] (see Availability of data and

691 materials). All transcriptomes were assembled de novo using the software Trinity [91], the

692 sequencing effort was a quarter of a lane (40million reads) per species on a HiSeq 2000 at Genome

693 Québec.

694

\section{3) Estimation of divergence and $d_{N} / d_{s}$ for pairs of orthologous genes}

We designed a customized pipeline (described below) in order to calculate divergence and

698 estimate the selective pressures along the coding regions of assembled transcriptomes of closely

699 related species previously positioned on our reference genome, using a 24-columns MegaBLAST

700 outputs. The code to perform analyses for this study is available as a git-based version control

701 repository on GitHub (https://github.com/CamilleTB/dNdS_cartography_Alvinella_speciation)

- Megablast

704 Because coding sequences are compared between divergent individuals within a given species or

705 between closely-related species, we performed a sequence-similarity search using each collection

706 of transcripts obtained for A. caudata and the two geographic forms of A. pompejana against the

707 entire Alvinella pompejana's genome with the software MegaBLAST implemented in NCBI

708 BLAST+ 2.2.30 nucleotide-nucleotide search, optimized for very similar sequences (set

709 expectation value cutoff $=10^{-15}$, maximum hits to show $=1$ ). 
712 The 24-columns MegaBLAST output was then filtered using a custom-made Perl script (called

713 "Paralog") to discriminate genes according to their position and occurrences in the genome. This

714 allowed us to rule out putative duplicated genes in our subsequent analyses. Based on the positions

715 of the hits on both scaffolds and transcripts, genes were separated into distinct categories, namely

716 scaffold paralog, tandemly repeated paralogs, allelic forms of a single gene in either genes with or

717 without introns. Scaffold paralogs correspond to coding sequences found on distinct scaffolds,

718 tandemly-repeated genes to sequences found at non-overlapping positions onto the same scaffold,

719 allelic forms of a gene corresponded to several transcripts matching exactly the same positions

720 onto a scaffold, and the two others categories were orthologous transcripts only found once into

721 the genome at a given scaffold position with a discrimination exon/uniq when the Megablast hits

722 corresponded or not to a succession of fragments with different positions both onto the scaffold

723 and the transcript (i.e. exonic regions). Paired orthologous sequences obtained in the two last

724 categories (exon and uniq) were then used to estimate divergence and associated $\mathrm{d}_{\mathrm{N}} / \mathrm{ds}$ ratios in

725 the pipeline.

726

727 - Search for coding DNA sequences (CDS) in pairwise alignments

728 Nucleic acid sequences were translated in the six reading frames to select for the longest CDS

729 between two subsequent stop codons. Coding sequences containing gaps, undetermined nucleic

730 acids $(\mathrm{N})$ or alternative frames without stop were removed. To avoid false positives and reduce the

731 risk of calculating erroneous $\mathrm{d}_{\mathrm{N}} / \mathrm{d}_{\mathrm{s}}$ values from non-coding or incorrectly framed sequences, we

732 performed a sequence-similarity search against the UniProt database using BlastP from NCBI

733 BLAST+2.2.30 (set expectation value cutoff $=10^{-10}$, maximum hits to show $\left.=1\right)$. Sequences with 
734 no annotation from UniProt with a CDS shorter than 300 nucleotides were removed from the 735 analysis.

- Divergence and $\mathrm{d}_{\mathrm{N}} / \mathrm{d}_{\mathrm{S}}$ calculation

738 Estimation of divergence, synonymous and nonsynonymous substitution rates and detection of

739 positive selection in protein-coding DNA sequences were performed using the program yn00 from

740 pamlX 1.2 in batch [92-93]. This program implements the method of Yang \& Nielsen

741 (implemented in [92]) to calculate $d_{s}$ and $d_{N}$ values from pairwise comparisons of protein-coding

742 DNA sequences. The weighing parameter that decides whether equal or unequal weighing will be

743 used when counting differences between codons was set to zero (= equal pathways between

744 codons) and we used the universal genetic code (icode $=0$ ). Output from yn00 was then parsed

745 and subsequently filtered from infinite values (99) when S.ds was equal to zero. When both $\mathrm{d}_{\mathrm{N}}$ and

746 ds values were null (about $70 \%$ of values obtained when comparing the northern and southern

747 forms of $A$. pompejana), $\mathrm{d}_{\mathrm{N}} / \mathrm{ds}$ was reset to zero. To avoid a division by zero, if $\mathrm{d}_{\mathrm{N}}$ was different

748 from zero but ds was zero, S.ds was reset to 1 assuming that at least one synonymous mutation

749 was missed by chance in the sequence.

750 To avoid any potential effect of greater divergence at non-synonymous sites possibly due to

751 sequencing errors when values of neutral divergence $\left(\mathrm{d}_{\mathrm{s}}\right)$ departed from zero, the significance of

752 all $\mathrm{d}_{\mathrm{N}} / \mathrm{d}_{\mathrm{s}}$ values greater than zero was tested using a custom-made pipeline. For that purpose, we

753 produced 1,000 random alignments of each pair of coding sequences using a bootstrap resampling

754 of codons (from the bootstrap option of codeML in PamlX 1.3.1). We then estimated the associated

$755 \mathrm{~d}_{\mathrm{N}}$ and $\mathrm{d}_{\mathrm{s}}$ for each resampled alignment, and calculated the difference (D) between each $\mathrm{d}_{\mathrm{N}}$ and $\mathrm{d}_{\mathrm{S}}$

756 resampled values in order to test whether the observed value of this difference was significantly 
757 greater than zero (i.e., fall outside the distribution of the pseudo-replicates). To this end, we

758 performed a unidirectional one-sample $z$-test for each resampled set of paired sequences and

759 adjusted p-values over the whole set of genes using the false discovery rate correction representing

760 the expected proportion of false positives [94].

\section{4) Identification of islands of divergence and/or adaptation}

To investigate the genomic architecture of molecular divergence of putative genes under 765 strong purifying $\left(\mathrm{d}_{\mathrm{N}} / \mathrm{ds}_{\mathrm{s}}\right.$ close to zero) or positive selection $\left(\mathrm{d}_{\mathrm{N}} / \mathrm{d}_{\mathrm{S}}>1\right)$ along chromosomes, both the

766 divergence and their $\mathrm{dN} / \mathrm{ds}$ associated values were positioned along the longest scaffolds $(>300,000$

767 bp with more than 5 genes per scaffold) of the draft genome of A. pompejana for each pairwise 768 comparisons (i.e., AP north vs AP south, and AP vs AC). According to the gene distribution along 769 each scaffold, three different types of patterns were characterized depending on the number and 770 level of clustering of divergent genes (divergence > 0.1) among scaffolds: (1) scaffolds without

771 divergent genes, (2) scaffolds with one or two isolated divergent genes and, (3) scaffolds carrying

772 a genes cluster of divergence corresponding to a putative island of speciation. The proportion of

773 each type was then calculated for the two sets of analyses. In addition, we calculated the mean

774 scaffold distance (d) between two divergent genes and its standard deviation $\left(\mathrm{s}^{2}(\mathrm{~d})\right)$ within each

775 scaffold. We then tested for contiguous distribution patterns of divergence along each scaffold

776 thanks to the Fisher's index of dispersion $\left(\mathrm{s}^{2}(\mathrm{~d}) /\right.$ mean $\left.(\mathrm{d})\right)$. Divergent genes are randomly

777 distributed when the index is equal to one, over-dispersed for values lower than one and aggregated

778 for values greater than one. 
We finally tested for a positive correlation between $\mathrm{d} / \mathrm{ds}$ and divergence ( $\mathrm{t}$ ) along scaffolds

781 (>300,000 bp with more than 5 genes per scaffold) using a home-made R script. Such a correlation

782 should indicate a genome-wide adaptive evolution of proteins assuming that, under neutral

783 evolution, $\mathrm{d}_{\mathrm{N}} / \mathrm{ds}_{\mathrm{s}}$ remains relatively constant before the time at which most of the synonymous sites

784 become saturated, and then slightly decreases with longer time of separate evolution.

785

786 Abbreviations

787 AP: Alvinella pompejana; AC: Alvinella caudata; EPR: East Pacific Rise; JDF: Juan de Fuca 788 Ridge; FDR: False discovery rate; MYA: Million years ago.

789 Acknowlegments

790 We would like to thank the captain and crews of the research vessel L'Atalante and the pilots and 791 associated teams of the manned submersible Nautile without which no specimen would have been

792 sampled. We are also very grateful to the chief-scientists of the oceanographic cruises Biospeedo 7932004 and Mescal 2010 for collecting Alvinella specimens and to S.C. Cary who kindly provided

794 in 2006 the AP specimen used to produce the genome. We thank Romain P. Boisseau for 795 considerable feedback on the manuscript and Ulysse Guyet or useful discussions on the statistical 796 analyses.

\section{Authors' contributions}

798 CTB and DJ performed analyses and wrote the manuscript. EB and DJ conceptualized, designed 799 and co-supervised the study. SH and DJ were in charge of the funded research project. ACC 800 supervised the AP genome project. $\mathrm{DB}, \mathrm{NN}, \mathrm{RC}$ and $\mathrm{EC}$ were involved in the AP genome 801 assembly, transcriptome assembly and mapping, and gene annotation. DJ, SH, and ACC edited 
802 and contributed to the proofreading of the manuscript. All authors read and approved the final

803 manuscript.

804 Funding

805 This study was supported by the Total Fondation. The funders had no role in conceptualizations

806 and study design, data collection and analysis, decision to publish, or preparation of the

807 manuscript.

808 Availability of data and materials

809 The AP genome: Two replicate runs of Illumina were performed onto the same individual (2 sets

810 of R1 and R2 compressed files of 33 Go: cf. SRA project under experiment accession numbers

811 ERX5990023-25; ERX5990051 and, run accession number: ERR6358489-91; ERR6358517) and,

812 used in combination to generate the first genome draft (V1). The reads of transcriptomes are

813 available from the Sequence Read Archive (SRA) database under accession numbers SRP076529

814 (Bioproject number: PRJNA325100) and SPX055399-402 (Bioproject number: PRJNA80027)),

815 and from the EST database under accession numbers FP489021 to FP539727 and FP539730 to

$816 \quad$ FP565142.

817

818 Declarations

819 Ethics approval and consent to participate

820 Not applicable.

821 Consent for publication

822 Not applicable.

823 Competing interests

824 All the authors declare no competing interests. 


\section{Authors details}

827 1Present address: Emlen Lab - BRB108, Division of Biological Sciences, The University of 828 Montana, Missoula, MT, USA

829 2Sorbonne Université, CNRS, UMR 7144 AD2M, Station Biologique de Roscoff, Place Georges

830 Teissier CS90074, 29688 Roscoff, France

\section{References}

835 [1] Tunnicliffe, V The biology of hydrothermal vents: ecology and evolution. Oceanogr Mar Biol 836 Annu Rev. 1991;29:319-407.

837 [2] Van Dover CL, German CR, Speer KG, Parson LM, Vrijenhoek RC. Evolution and 838 biogeography of deep-sea vent and seep invertebrates. Science. 2002;295(5558):1253-57.

839 [3] Plouviez S, Shank TM, Faure B, Daguin-Thiebaut C, Viard F, Lallier FH, Jollivet D. 840 Comparative phylogeography among hydrothermal vent species along the East Pacific Rise 841 reveals vicariant processes and population expansion in the South. Mol. Ecol. 2009;18(18):390384217.

843 [4] Matabos M, Jollivet D. Revisiting the Lepetodrilus elevatus species complex (Vetigastropoda:

844 Lepetodrilidae), using samples from the Galápagos and Guaymas hydrothermal vent systems. J 845 Moll Stud. 2019;85(1):154-65.

846 [5] Lutz RA. Dispersal of organisms at deep-sea hydrothermal vents: a review. Oceanol Acta. $847 \quad$ Special Issue. 1988;8:23-30. 
848 [6] Tyler PA, Young CM. Reproduction and dispersal at vents and cold seeps. J mar Biol Ass UK.

849 1999;79(2):193-208.

850 [7] Jollivet D. Specific and genetic diversity at deep-sea hydrothermal vents: an overview. Biodiv 851 Conserv. 1996;5(12):1619-53.

852 [8] Vrijenhoek RC. Gene flow and genetic diversity in naturally fragmented metapopulations of 853 deep-sea hydrothermal vent animals. J Hered. 1997;88(4):285-93.

854 [9] Jollivet D, Chevaldonné P, Planque B. Hydrothermal-vent alvinellid polychaete dispersal in 855 the Eastern Pacific. 2. a metapopulation model based on habitat shifts. Evolution. 856 1999;53(4):1128-42.

857 [10] Johnson KS, Childress JJ, Beehler CL. Short-term temperature variability in the Rose Garden 858 hydrothermal vent field: an unstable deep-sea environment. Deep Sea Res Part A. 1988;35(10859 11):1711-21.

860 [11] Le Bris N, Sarradin PM, Caprais JC. Contrasted sulphide chemistries in the environment of $86113^{\circ} \mathrm{N}$ EPR vent fauna. Deep Sea Res Part I. 2003;50(6):737-47.

862 [12] Matabos M, Le Bris N, Pendlebury S, Thiébaut E. Role of physico-chemical environment on 863 gastropod assemblages at hydrothermal vents on the East Pacific Rise (13 $\left.{ }^{\circ} \mathrm{N} / \mathrm{EPR}\right)$. J mar Biol Ass $864 \quad$ UK. 2008;88(5):995-1008.

865 [13] O’Mullan GD, Maas PAY, Lutz RA, Vrijenhoek RC. A hybrid zone between hydrothermal 866 vent mussels (Bivalvia: Mytilidae) from the Mid-Atlantic Ridge. Mol Ecol. 2001;10(12):2819-31. 867 [14] Johnson SB, Won Y-J, Harvey JBJ, Vrijenhoek RC. A hybrid zone between Bathymodiolus 868 mussel lineages from Eastern Pacific hydrothermal vents. BMC Evol Biol. 2013;13(1):21. 
869 [15] Plouviez S, Le Guen D, Lecompte O, Lallier FH, Jollivet D. Determining gene flow and the

870 influence of selection across the equatorial barrier of the East Pacific Rise in the tube-dwelling

871 polychaete Alvinella pompejana. BMC Evol Biol 2010;10(1):220.

872 [16] Plouviez, S, Faure B, Le Guen D, Lallier FH, Bierne N, Jollivet D. A new barrier to dispersal

873 trapped old genetic clines that escaped the Easter Microplate tension zone of the Pacific vent

874 mussels. PLoS One. 2013;8(12):e81555.

875 [17] Matabos M, Plouviez S, Hourdez S, Desbruyères D, Legendre P, Warén A, Jollivet D,

876 Thiébaut E. Faunal changes and geographic crypticism indicate the occurrence of a biogeographic

877 transition zone along the Southern East Pacific Rise. J Biogeogr. 2011;38(3):575-94.

878 [18] Won Y-J, Hallam SJ, O’Mullan GD, Vrijenhoek RC. Cytonuclear disequilibrium in a hybrid 879 zone involving deep-sea hydrothermal vent mussels of the genus Bathymodiolus. Mol Ecol. $880 \quad 2003 ; 12(11): 3185-90$.

881 [19] Roux C, Fraïsse C, Romiguier J, Anciaux Y, Galtier N, Bierne N. Shedding light on the grey 882 zone of speciation along a continuum of genomic divergence. PLoS 883 biology. 2016;14(12):e2000234.

884 [20] Wood TE, Takebayashi N, Barker MS, Mayrose I, Greenspoon PB, Rieseberg LH. The 885 frequency of polyploid speciation in vascular plants. Proc Nat Acad Sci USA. $886 \quad 2009 ; 106(33): 13875-79$.

887 [21] De Storme N, Mason A. Plant speciation through chromosome instability and ploidy change: 888 cellular mechanisms, molecular factors and evolutionary relevance. Current Plant Biol. $8892014 ; 1: 10-33$. 
890 [22] Schöfl G, Heckel DG, Groot AT. Time-shifted reproductive behaviours among fall 891 armyworm (Noctuidae: Spodoptera frugiperda) host strains: evidence for differing modes of 892 inheritance. J Evol Biol. 2009;22(7):1447-59.

893 [23] Monteiro CA, Serrão EA, Pearson GA. Prezygotic barriers to hybridization in marine 894 broadcast spawners: reproductive timing and mating system variation. PLoS One. $895 \quad 2012 ; 7(4): \mathrm{e} 35978$.

896 [24] Drès M, Mallet J. Host races in plant-feeding insects and their importance in sympatric 897 speciation. Phil Trans Roy Soc London, Ser B. 2002;357(1420):471-92.

898 [25] Rundle HD, Nosil P. Ecological speciation. Ecol Lett. 2005;8(3):336-52.

899 [26] Butlin RK, Galindo J, Grahame JW. Sympatric, parapatric or allopatric: the most important 900 way to classify speciation? Phil Trans Roy Soc B. 2008;363(1506):2997-3007.

901 [27] Mallet J. Hybridization, ecological races and the nature of species: empirical evidence for the 902 ease of speciation. Phil Trans Roy Soc B. 2008;363(1506):2971-86.

903 [28] Berner D, Grandchamp A-C, Hendry AP. Variable progress toward ecological speciation in 904 parapatry: Stickleback across eight lake-stream transitions. Evolution. 2009;63(7):1740-53.

905 [29] Hendry AP, Bolnick DI, Berner D, Peichel CL. Along the speciation continuum in 906 Sticklebacks. J Fish Biol. 2009;75(8):2000-36.

907 [30] Nosil P, Funk DJ, Ortiz-Barrientos D. Divergent selection and heterogeneous genomic 908 divergence. Mol Ecol. 2009;18(3):375-402.

909 [31] Schluter D. Evidence for ecological speciation and its alternative. Science. $910 \quad 2009 ; 323(5915): 737-41$.

911 [32] Gagnaire PA. Comparative genomics approach to evolutionary process connectivity. Evol 912 Appl. 2020;13(6):1320-34. 
913 [33] Seehausen O, Butlin RK, Keller I, Wagner CE, Boughman JW, Hohenlohe PA, Peichel CL,

914 et al. Genomics and the origin of species. Nature Rev Genet 2014;15(3):176-92.

915 [34] Wolf JBW, Ellegren H. Making sense of genomic islands of differentiation in light of 916 speciation. Nature Rev Genet. 2016;18(2):87-100.

917 [35] Turner TL, Hahn MW, Nuzhdin SV. Genomic islands of speciation in Anopheles gambiae.

$918 \quad$ PLoS Biol. 2005;3(9):e285.

919 [36] Via S, West J. The genetic mosaic suggests a new role for hitchhiking in ecological 920 speciation. Mol Ecol. 2008;17(19):4334-45.

921 [37] Cruickshank TE, Hahn MW. Reanalysis suggests that genomic islands of speciation are due 922 to reduced diversity, not reduced gene flow. Mol Ecol. 2014;23(13):3133-3157.

923 [38] Feder JL, Nosil P. The efficacy of divergence hitchhiking in generating genomic islands 924 during ecological speciation. Evolution. 2010;64(6):1729-47.

925 [39] Hofer T, Foll M, Excoffier L. Evolutionary forces shaping genomic islands of population 926 differentiation in humans. BMC Genomics. 2012;13(1):107.

927 [40] Larson WA, Limborg MT, McKinney GJ, Schindler DE, Seeb JE, Seeb LW. Genomic islands 928 of divergence linked to ecotypic variation in Sockeye salmon. Mol Ecol. 2017;26(2):554-70.

929 [41] Duranton M, Allal F, Fraïsse C, Bierne N, Bonhomme F, Gagnaire P-A. The origin and 930 remolding of genomic islands of differentiation in the European sea bass. Nature. Comm. $931 \quad 2018 ; 9(1): 1-11$.

932 [42] Tavares H, Whibley A, Field DL, Bradley D, Couchman M, Copsey L, Elleouet J, et al. 933 Selection and gene flow shape genomic islands that control floral guides. Proc Nat Acad Sci USA. 934 2018;115(43):11006-11011. 
935 [43] Feder JL, Egan SP, Nosil P. The genomics of speciation-with-gene-flow. Trends Genet. 936 2012;28(7):342-50.

937 [44] Feder JL, Nosil P, Wacholder AC, Egan SP, Berlocher SH, Flaxman SM. Genome-Wide 938 congealing and rapid transitions across the speciation continuum during speciation with gene flow. 939 J Hered. 2014;105(S1):810-20.

940 [45] Flaxman SM, Wacholder AC, Feder JL, Nosil P. Theoretical models of the influence of 941 genomic architecture on the dynamics of speciation. Mol Ecol. 2014;23(16):4074-88.

942 [46] Tittes S, Kane NC. The genomics of adaptation, divergence and speciation: a congealing 943 theory. Mol Ecol. 2014;23(16):3938-40.

944 [47] Chevaldonné P, Desbruyères D, Childress JJ. ... and some even hotter. Nature. 945 1992;359(6396):593-594.

946 [48] Cary SC, Shank T, Stein J. Worms bask in extreme 947 temperatures. Nature. 1998;391(6667):545-546.

948 [49] Desbruyères, D, Laubier L. Alvinella pompejana gen. sp. nov., ampharetidae aberrant des 949 sources hydrothermales de la ride Est-Pacifique. Oceanol Acta. 1980;3(3):267-274.

950 [50] Desbruyères, D, Laubier L. Les Alvinellidae, une famille nouvelle d'annélides polychètes 951 inféodées aux sources hydrothermales sous-marines: systématique, biologie et écologie. Can J 952 Zool 1986;64(10):2227-45.

953 [51] Autem M, Salvidio S, Pasteur N, Desbruyères D, Laubier L. Mise en évidence de l'isolement 954 génétique de deux formes sympatriques d'Alvinella pompejana (Polychaeta: Ampharetidae), 955 annélides inféodées aux sites hydrothermaux actifs de la dorsale du Pacifique Oriental. C R Acad 956 Sci Paris. 1985;301:131-35. 
957 [52] Jollivet D, Desbruyères D, Ladrat C, Laubier L. Evidence for differences in the allozyme 958 thermostability of deep-sea hydrothermal vent polychaetes (Alvinellidae): a possible selection by 959 habitat. Mar Ecol Prog Ser. 1995;123(1-3):125-136.

960 [53] Faure B, Jollivet D, Tanguy A, Bonhomme F, Bierne N. Speciation in the deep sea: multi961 locus analysis of divergence and gene flow between two hybridizing species of hydrothermal vent 962 mussels. PLoS One. 2009;4(8):e6485.

963 [54] Kimura M. Preponderance of synonymous changes as evidence for the neutral theory of 964 molecular evolution. Nature. 1977; 267(5608):275-76.

965 [55] Stoletzki N, Eyre-Walker A. Synonymous codon usage in Escherichia coli: selection for 966 translational accuracy. Mol Biol Evol. 2007;24(2):374-81.

967 [56] Carbotte S, Macdonald K. East Pacific Rise $8^{\circ}-10^{\circ} 30^{\prime} \mathrm{N}$ : Evolution of ridge segments and 968 discontinuities from SeaMARC II and three-dimensional magnetic studies. J Geophys Res: Solid 969 Earth. 1992;97(B5):6959-82.

970 [57] Fontanillas E, Galzitskaya OV, Lecompte O, Lobanov MY, Tanguy A, Mary J, Girguis PR, 971 Hourdez S, Jollivet D. Proteome evolution of deep-sea hydrothermal vent alvinellid polychaetes 972 supports the ancestry of thermophily and subsequent adaptation to cold in some lineages. Genome 973 Biol Evol 2017;9(2):279-296.

974 [58] Mikkelsen PM. Speciation in modern marine bivalves (Mollusca: Bivalvia): insights from the 975 published record. Am Malacol Bull. 2011;29(1-2):217-45.

976 [59] Rat Genome Sequencing Project Consortium. Genome sequence of the brown Norway rat 977 yields insights into mammalian evolution. Nature. 2004;428(6982):493-521.

978 [60] Gaut B, Yang L, Takuno S, Eguiarte LE. The patterns and causes of variation in plant 979 nucleotide substitution rates. Ann Rev Ecol Evol Syst. 2011; 42(1):245-66. 
980 [61] Eyre-Walker A, Keightley PD, Smith NGC, Gaffney D. Quantifying the slightly deleterious 981 mutation model of molecular evolution. Mol Biol Evol. 2002; 19(12):2142-49.

982 [62] Hurtado LA, Lutz RA, Vrijenhoek RC. Distinct patterns of genetic differentiation among 983 annelids of Eastern Pacific hydrothermal vents. Mol Ecol. 2004;13(9):2603-15.

984 [63] Jang S-J, Park E, Lee W-K, Johnson SB, Vrijenhoek RC, Won Y-J. Population subdivision 985 of hydrothermal vent polychaete Alvinella pompejana across Equatorial and Easter Microplate 986 boundaries. BMC Evol Biol. 2016;16(1):235.

987 [64] Orr HA, Turelli M. The evolution of postzygotic isolation: accumulating Dobzhansky-Muller 988 incompatibilities. Evolution. 2001;55(6):1085-94.

989 [65] Garrigan D, Kingan SB, Geneva AJ, Andolfatto P, Clark AG, Thornton KR, Presgraves DC. 990 Genome sequencing reveals complex speciation in the Drosophila simulans clade. Genome Res. $991 \quad 2012 ; 22(8): 1499-1511$.

992 [66] Palmer ME, Feldman MW. Dynamics of hybrid incompatibility in gene networks in a constant 993 environment. Evolution. 2009;63(2):418-31.

994 [67] Palumbi SR. Genetic divergence, reproductive isolation, and marine speciation. Ann Rev Ecol 995 Syst. 1994;25(1):547-572.

996 [68] Orr HA. The genetic basis of reproductive isolation: insights from Drosophila. Proc Nat Acad 997 Sci USA. 2005;102(1):6522-26.

998 [69] Presgraves DC. The molecular evolutionary basis of species formation. Nature Rev Genet. 999 2010;11(3):175-80.

1000 [70] Castillo, DM, Barbash DA. Moving speciation genetics forward: modern techniques build on 1001 foundational studies in Drosophila. Genetics. 2017;207(3):825-42. 
1002 [71] Jouin-Toulmond C, Mozzo M, Hourdez S. Ultrastructure of spermatozoa in four species of 1003 Alvinellidae (Annelida: Polychaeta). Cah. Biol. Mar. 2002;43(3/4):391-394.

1004 [72] Desbruyères D, Chevaldonné P, Alayse A-M, Jollivet D, Lallier FH, Jouin-Toulmond C, Zal 1005 F, et al. Biology and Ecology of the 'Pompeii Worm' (Alvinella pompejana Desbruyères and 1006 Laubier), a normal dweller of an extreme deep-sea environment: a synthesis of current knowledge 1007 and recent developments. Deep Sea Res Part II: Topical Studies in Oceanography. 1008 1998;45(1):383-422.

1009 [73] Breusing C, Castel J, Yang Y, Broquet T, Sun J, Jollivet D, Qian P-Y, Beinart RA. Global 1010 16S rRNA diversity of provannid snail endosymbionts from Indo-Pacific deep-sea hydrothermal 1011 vents. Environ Microbiol Reports, 2021;in press.

1012 [74] Papot C, Massol F, Jollivet D, Tasiemski A. Antagonistic evolution of an antibiotic and its 1013 molecular chaperone: how to maintain a vital ectosymbiosis in a highly fluctuating habitat. 1014 Scientific Reports. 2017;7(1):1-14.

1015 [75] Swanson, WJ, Vacquier VD. The rapid evolution of reproductive proteins. Nature Rev Genet. $10162002 ; 3(2): 137-44$.

1017 [76] Chevaldonné, P, Desbruyères D, Le Haître M. Time-series of temperature from three deep1018 sea hydrothermal vent sites. Deep Sea Res Part A. 1991;38(11):1417-30.

1019 [77] Le Bris N, Gaill F. How does the annelid Alvinella pompejana deal with an extreme 1020 hydrothermal environment? Rev Environ Sci Biotechnol. 2006;6(1):197.

1021 [78] Gaill F, Wiedemann H, Mann K, Kühn K, Timpl R, Engel J. Molecular characterization of 1022 cuticle and interstitial collagens from worms collected at deep sea hydrothermal vents. J Mol Biol. 1023 1991;221(1):209-23. 
1024 [79] Cary, SC, Cottrell MT, Stein JL, Camacho F, Desbruyères D. Molecular identification and 1025 localization of filamentous symbiotic bacteria associated with the hydrothermal vent annelid 1026 Alvinella pompejana. Appl Environ Microbiol. 1997;63(3):1124-30.

1027 [80] Phleger, CF, Nelson MM, Groce AK, Cary SC, Coyne K, Gibson JAE, Nichols PD. Lipid 1028 biomarkers of deep-sea hydrothermal vent polychaetes - Alvinella pompejana, A. caudata, 1029 Paralvinella grasslei and Hesiolyra bergi. Deep Sea Res Part I. 2005;52(12):2333-52.

1030 [81] Toulmond A, Slitine FEI, De Frescheville J, Jouin C. Extracellular hemoglobins of 1031 hydrothermal vent annelids: structural and functional characteristics in three alvinellid species. 1032 Biol Bull. 1990;179(3):366-73.

1033 [82] Jouin-Toulmond C, Augustin D, Desbruyères D, Toulmond A. The gas transfer system in 1034 alvinellids (Annelida Polychaeta, Terebellida). anatomy and ultrastructure of the anterior 1035 circulatory system and characterization of a coelomic, intracellular haemoglobin, Cah Biol 1036 Mar. 1996;37(2):135-152.

1037 [83] Chevaldonné P, Jollivet D, Desbruyères D, Lutz RA, Vrijenhoek RC. Sister-species of Eastern 1038 Pacific hydrothermal vent worms (Ampharetidae, Alvinellidae, Vestimentifera) provide new 1039 mitochondrial COI clock calibration. Cah Biol Mar. 2002;43(3-4):367-70.

1040 [84] Sicot F-X, Mesnage M, Masselot M, Exposito J-Y, Garrone R, Deutsch J, Gaill F. Molecular 1041 adaptation to an extreme environment: origin of the thermal stability of the Pompeii worm 1042 collagen. J Mol Biol. 2000;302(4):811-20.

1043 [85] Garrett SC, Rosenthal JJC. A role for A-to-I RNA editing in temperature adaptation. 1044 Physiology. 2012;27(6):362-69. 
1045 [86] Pradillon F, Zbinden M, Mullineaux LS, Gaill F. Colonisation of newly-opened habitat by a 1046 pioneer species, Alvinella pompejana (Polychaeta: Alvinellidae), at East Pacific Rise vent 1047 sites. Mar Ecol Prog Ser. 2005;302:147-157.

1048 [87] Chevaldonné P, Jollivet D. Videoscopic study of deep-sea hydrothermal vent alvinellid 1049 polychaete populations: estimation of biomass and behaviour. Mar Ecol Prog Ser. 1993;95(3):2511050262.

1051 [88] Lee PN, McFall-Ngai MJ, Callaerts P, de Couet HG. Preparation of genomic DNA from 1052 Hawaiian bobtail squid (Euprymna scolopes) tissue by cesium chloride gradient 1053 centrifugation. Cold Spring Harbor Protocols. 2009;11,pdb-prot5319.

1054 [89] Yao B, Zhao Y, Zhang H, Zhang M, Liu M, Liu H, Li J. Sequencing and de novo analysis of 1055 the Chinese Sika deer antler-tip transcriptome during the ossification stage using Illumina RNA1056 Seq technology. Biotechnol lett. 2012;34(5):813-822.

1057 [90] Gagnière N, Jollivet D, Boutet I, Brélivet Y, Busso D, Da Silva C, Gaill F, et al. Insights into 1058 metazoan evolution from Alvinella pompejana cDNAs. BMC Genomics. 2010;11(1):634.

1059 [91] Bankar KG, Todur VN, Shukla RN, Vasudevan M. Ameliorated de novo transcriptome 1060 assembly using Illumina paired end sequence data with Trinity Assembler. Genomics 1061 data. 2015;5:352-359.

1062 [92] Yang Z. PAML 4: Phylogenetic Analysis by Maximum Likelihood. Mol Biol Evol. $10632007 ; 24(8): 1586-91$.

1064 [93] Xu B, Yang Z. PamlX: a graphical user interface for PAML. Mol Biol Evol. 2013;30 1065 (12):2723-24.

1066 [94] Benjamini Y, Hochberg Y. Controlling the false discovery rate: a practical and powerful 1067 approach to multiple testing. J Roy Stat Soc, ser B. 1995;57(1):289-300. 


\section{Supplementary Files}

This is a list of supplementary files associated with this preprint. Click to download.

- SupTable1Genesannotation.xlsx

- SuppTable2metrics.xlsx

- Supplementarytableslegends.docx 